Beyond Imitation, Without Limitations:

\title{
A Student Music Therapist Supports the Participation and Development of Young People with Profound and Multiple Learning Difficulties in a School Setting
}

An exegesis submitted to Massey University and Victoria University of

Wellington in partial fulfilment for the degree of

Master of Music Therapy

New Zealand School of Music

Conor Clerkin 
This exploratory study sought to uncover the methods and techniques a student music therapist employed to support the participation of young people with complex needs in a school setting. Individual music therapy sessions were carried out over nine months, and clinical documentation was generated throughout this period. Data sources included clinical notes, a reflective journal, and audiovisual recordings from music therapy sessions. Once a research question had been established, the existing data was reviewed retrospectively through a process of secondary analysis, and both inductive and deductive methods of analysis were employed to enable meaningful interpretations of the data to occur. A process of coding and thematically linking elements of music therapy practice allowed for a model of understanding to emerge, and findings suggest that the behaviours and strategies utilised by the student music therapist to support the young people's participation in music therapy fell into three thematic groupings: creating a collaborative environment; following and leading; and dynamic flow. Themes are defined and the codes within elaborated upon, with case examples from the data included as appropriate to illustrate their meaning. Findings are discussed, and links are made to the literature in relevant fields. While results cannot be generalised to other settings, it is hoped that the detail and in depth analysis of practice provide a thorough and meaningful insight into the types of interaction that can occur in music therapy with young people with complex needs, and the value of specific supports to participation identified in this research. 


\section{ACKNOWLEDGEMENTS}

The journey of learning how to become a music therapist and researcher has been an enjoyable, interesting, challenging, but altogether invigorating experience for me. My life will never be the same, and it would not have been the same without:

The lovely land and people of Wellington - the brightness and warmth of this city have kept me bubbly and motivated throughout my studies.

My supervisor Sarah Hoskyns, who in reality was much more than a supervisor but a real source of support, friendship, humour, and inspiration throughout this entire learning curve. I have great admiration for you (and your Irish accent), and enjoyed our deep and meaningful talks. Thank you.

The endlessly insightful and articulate Daphne Rickson. Your ability to teach and pass on wisdom is in my opinion up there with the best.

All of my classmates, $1^{\text {st }}$ and $2^{\text {nd }}$ year! It has been an absolute pleasure getting to know each and every one of you, and I would like to acknowledge the importance of the support and friendship you have given me.

Everyone at the school, students and staff. What an incredible and unforgettable experience it was to work and play with you all. Keep being fantastic!

Uncle Matthew, for always being there for a chat, and when I really needed you. It was very special being out here with you for these two rollercoaster years.

My wonderful and loving family: Mum, Dad, Ciaran, Fionnuala, Brendan, and Aidan. I am very lucky to have all of you in my life. I have always felt like you have all been behind me every step of the way, encouraging me forward, and believing in me to be the best I can be. 
TABLE OF CONTENTS

Abstract

Acknowledgements ii

Table of Contents___ _ iii

List of Figures

List of Appendices__ vi

Introduction 1

The Setting _ 1

Disability Terminology___ 2

Approach to Practice, Research and Understanding___ 3

Personal Position

Music Therapy in Practice___ 5

Exegesis Format__ 6

Literature Review___ 7

Introduction__ 7

Music and Disability___ 8

Music and Participation__ 9

Recent Music Research in Special Needs___ 11

Working within a Transdisciplinary Team

Summary__ 14

Methodology__ 15

Philosophy and Research Approach__ 15

Method of Inquiry ___ 15

Data Collection and Sources___ 16 
Data Analysis

Ethical Issues

Findings 21

Clinical Vignette 21

Creating a Collaborative Environment 25

Following and Leading 30

Dynamic Flow 43

Summary 47

Discussion 48

Conclusions 55

References 57

Appendices 65 
Figure 1: Supporting Participation Themes 25

Figure 2: Theme One Codes 25

Figure 3: Theme Two Codes 31

Figure 4: Theme Three Codes 44 


\section{LIST OF APPENDICES}

Appendix 1: Glossary of Terms

Appendix 2: Cover Letter for Family 66

Appendix 3: Information Sheet for Family 67

Appendix 4: Consent Form for Family 69

Appendix 5: Cover Letter for School 70

Appendix 6: Information Sheet for Staff 72

Appendix 7: Consent Form for Staff 74

Appendix 8: Example of Song Composed in Music Therapy 75

Appendix 9: Examples of Early and Later Coding 77

Appendix 10: Stages of Thought Progress in Analysis 79 


\section{INTRODUCTION}

"For young children with no language, there is still music. For the young child with limited movement, there is still music. For a child who cannot see or touch objects in the environment, there is still music" (Schwartz, 2008, p.xiii)

The question for this research emerged during a 750-hour long clinical placement as a music therapy student in a school for young people with profound and multiple learning difficulties $(P M L D S)^{1}$. During this period I reviewed my own clinical practice in order to uncover what appeared to work well in assisting students to participate in music therapy. As most of the sessions undertaken were one-on-one with individual students, I decided to focus my research analysis on the experiences and aspects of my practice when working with individuals. The central inquiry that guided this study is as follows:

How can I support the needs of the school's young people in music therapy in a way that facilitates their participation and contributes towards their holistic development?

The title preface 'beyond imitation, without limitations' refers to my understanding and thoughts about people with complex needs. By 'beyond imitation', I mean that there are many more ways that these young people can interact beyond others simply imitating their sounds, although this is indeed a valuable tool when used appropriately. Additionally, 'beyond imitation' recognises that every person is an individual with their own inherent value, and that nobody can replicate or truly know who another is and what their capabilities are. 'Without limitations' represents my belief in the importance of people of all ages and abilities striving for and becoming the best person they can be, without needing to be perceived by others in light of what they have not yet learned.

\section{THE SETTING}

The school offers a holistic approach to the education of young people between the ages of 5-21 from a variety of ethnic backgrounds. To enrol at the school, students must have a significant physical disability and be verified as having very high needs under the terms of the Ongoing Resourcing Scheme (see Ministry of Education, 2012). Most students in the school have a diagnosis of cerebral palsy and this is understood to be the primary cause of any physical impairments for students who have the condition. Teaching and therapeutic staff work with the families of students to help them achieve their learning and functional potential in communicative, social, personal, physical and emotional domains towards a

\footnotetext{
${ }^{1}$ See Appendix 1: Glossary of Terms for explanation of italicised words
} 
goal of holistic wellbeing. These goals are guided by the key competencies framework of the New Zealand curriculum, and expressed within the Individual Education Plan (IEP) of every student.

For the duration of my research the school also employed a full-time music therapist, whom I shall call Ann². Her presence and knowledge of students were helpful in my preparation for working with individuals. She also supported and guided my own reflections on sessions when available, in the role of a clinical supervisor; I believe that this support helped me to increase my self-awareness and ability to question my own assumptions with regard to the work I did with students. In the initial stages of my placement we negotiated a feasible music therapy timetable, ensuring that student needs and goals were well thought through before entering into music therapy.

The school offered a transdisciplinary approach to the growth and development of its students. When arranging times to offer music therapy to various students, it was necessary to organise and negotiate timetables in conjunction with other teachers and therapists so that students' days were efficiently constructed for a wide and varied array of learning experiences within therapeutic, educational, and social settings. Once established, music therapy sessions were consistently held at the same times for each student, although occasionally unexpected instances occurred that meant sessions had to be postponed, such as when students were sick or absent.

\section{DISABILITY TERMINOLOGY}

The language we use in relation to people with disability is always changing (Adamek \& Darrow, 2010), and the terminology we use may both reflect our perceptions of those people and influence the attitudes of others towards them (Auslander \& Gold, 1999). Over the years many different terms have been used to describe those who have not developed typically, whether due to a condition caused at birth or a congenital disorder such as Down syndrome or autism. In recent times, it seems to have become more acceptable to ascribe terms such as 'special needs', 'complex needs' or 'very high needs' to people with various kinds of disability. The term 'intellectual disability' is also coming into favour in the US, gradually replacing the increasingly outdated label of 'mental retardation' (Brown \& Jellison, 2012). In addition, the term 'profound and multiple learning difficulties' (PMLDs) has become a widely accepted way to describe those people who are perceived to function

\footnotetext{
${ }^{2}$ Name changed for reasons of anonymity.
} 
at the level expected of a 1-2 year old, due to having more than one disability in cognitive, sensory, social, or physical domains (see Bellamy, Croot, Bush, Berry \& Smith, 2010; Ockelford, 2008; Ware, 2003). In respect of people with various levels of disability, it has also become standard practice to place the person before the perceived disability, so as not to allow the disability to define them as a person. This is my preferred way of writing, as I feel it allows me to value the person to the fullest extent possible. Throughout this paper, I will use the terms complex needs, special needs, and PMLDs to mean the same things in relation to the same group of people, while also referring to the word disability as an overarching term for all three.

\section{APPROACH TO PRACTICE, RESEARCH AND UNDERSTANDING}

As a music therapist, I consider my approach to be client-centred (Rogers, 1995). I have found this approach to be particularly important when working with people with PMLDs, as it focuses on existing strengths and provides greater opportunity for the other person to participate actively in music using whatever abilities and means are available to them. This participation would manifest itself as a facial expression, physical movement, vocalisation, or any noticeable change in presentation that acted as a form of communication to me that indicated the person appeared to be thinking, processing, and responding to musical activities.

It can be very challenging to communicate meaningfully with people with PMLDs (Lee \& McFerran, 2012), and nearly all of the students with whom I worked during my clinical practice and research had no existing verbal abilities. Without an ability to express clearly what they were feeling through speech, or my ability to interpret with reasonable certainty the meaning that lay behind a particular idiosyncratic behaviour, movement or vocalisation of students, it seemed clear that an open-ended exploratory approach to my practice would be appropriate. Any investigation into the value of my specific practices had to take into account the fact that it was very difficult to ever know how the other person was feeling or thinking at any point ${ }^{3}$. As a result I needed to concentrate on a rich description of the subtleties and tiny details of student behaviour in order to build up a picture of the music therapy experience. As my knowledge of students' personalities, behaviours, and abilities expanded, I used this to inform the content of further sessions. I was not interested to

\footnotetext{
${ }^{3}$ Weekly supervision meetings with Ann helped me to broaden my view of the different possible realities in music therapy sessions experienced by myself and students.
} 
prove or disprove anything, but rather build an understanding that could help to enhance student wellbeing.

\section{PERSONAL POSITION}

I have always been heavily invested in musical activities, playing numerous instruments and being part of many music groups. When I got older and became proficient enough in my musical abilities, I began teaching in different settings, at home and abroad, independently and as part of educational institutions. As I gained experience in teaching, I learned that every student learned at different rates and in unique ways. I could not simply follow a strict plan as some students would invariably become unstuck at certain parts, which meant that I would have to be creative and responsive to students' needs in the moment to help them feel comfortable, understand, and develop musically. It was difficult to plan for these times, but in my experience these spontaneous moments of change often resulted in the creation of valuable new methods and techniques for connecting with students and helping them to learn in ways that engaged both teacher and student.

Preceding my adult experiences, I have encountered some instances where the issue of disability has also come to the fore. I can recall when I was in primary school a student of the same age as me who had a physical disability in his lower body. This disability caused him to walk in an unusual way that was often made fun of by others. Similarly in secondary school I remember a boy in my year who, in retrospect, was clearly on the autistic spectrum. He too was bullied and isolated in school due to his socially unusual behaviours and speech impediments. In both instances, I did little or nothing to help the boys build friendships and confidence, mostly due to my lack of understanding of their conditions and fear of being ostracised by classmates. The sense that I could have been more aware of and proactive in supporting others is a strong motivating factor behind my desire to enhance understanding about disability, and to not let others with disabilities experience similar detrimental prejudices in future.

In the course of my life I have developed a philosophical perspective that is individualistic, idealistic, social, and critically reflective. I believe that while we are all individuals, we are nonetheless interconnected and inter-related in everything we do. As such, I also believe that disability does not simply begin and end within a person - it is a shared phenomenon between all of society, and all must work together to alleviate the difficulties and problems associated with it. I have found that the more time I spend with people with disabilities, the 
more I become aware of how intelligent and responsive they are to the most normal of activities and interactions. Such a realisation on my part has meant that I can adjust my position and be more open to different ways of communicating. To reach a point in a relationship where a person will react to and interact with me in a special musical way is extremely satisfying. This does not come easily, and it is this challenge that motivates me to continue learning about people who have less means of communication than most, using music as the tool for understanding and development.

It may be easy for people to make assumptions about those with disabilities when they know little or nothing about their personality, life, or circumstances. However, I wonder how someone would feel if the tables were turned and they had a brother or sister who was considered to have a disability and had to listen to the disrespectful behaviours of others towards them? Like in a family, I believe that it is only when you spend significant quality time with someone that you can learn to see how talented, caring, and intelligent they really are.

\section{MUSIC THERAPY IN PRACTICE}

Music therapy sessions in the school were mostly done on an individual basis, with students taken out of class so that we could play music in a private room without disturbance; this is known as the 'pull-out' model (Adamek \& Darrow, 2010). Brown and Jellison (2012) claim that working with students outside of the classroom is common practice for music therapists in schools. Group sessions were also carried out every week; however, these were much less common and were influenced by the presence of other staff members.

Before doing any sessions, I discussed with Ann as to what students she thought would benefit from music therapy. Through these talks and also through meetings with teachers of students, I learned useful information about students that helped me decide and organise my music therapy schedule in the school. As Adamek and Darrow (2010) state, "communication with the classroom teacher is essential to gain insight into the best ways to work with a particular student" (p.56), and I always tried to talk with teachers regularly in order to maintain a healthy and collaborative relationship. I also researched about students' abilities and goals in their respective IEPs in order to link my work further with the rest of the transdisciplinary team.

Typically I met students in their classroom and brought them to the music room myself. Activities undertaken in sessions included improvising, performing songs, singing, and 
moving to music. Session structures for all students were developed as our relationship and knowledge of each other progressed, and gradually came to include a series of activities that I felt through experience the student enjoyed and could relate to. For consistency and clarity, I have chosen to adopt Wigram's (2004) definitions of 'musical techniques' and 'therapeutic methods' ${ }^{4}$ when describing aspects of my music therapy work; he explains the former as "a way of playing or singing where the style, modality and elements are described by musical parameters"; the latter "refers to a way of acting and behaving where the intention, approach, or frame is determined by therapeutic parameters" (p.34).

\section{EXEGESIS FORMAT}

Following this broad introduction to the research, the literature review will aim to orientate the reader with regards to current discourses on the concepts of disability, music therapy and participation. It will aim to create a context through which the current research can be viewed as part of ongoing investigations into the field of music therapy and disability. The methodology section outlines the procedures I carried out with regard to data collection and analysis, as well as the beliefs and philosophical understandings that underpin these methods. Findings are then revealed, discussed, and suggestions for further research offered.

\footnotetext{
${ }^{4}$ I may use the word 'strategies' interchangeably with methods to mean the same thing.
} 


\section{LITERATURE REVIEW}

\section{INTRODUCTION}

Music is a normalising and inclusive activity in which people of all abilities can participate (Adamek, 2002). Musical development has been said to persist throughout life (Gembris, 2012), and as well as participating in musical activities for music's sake, musical activity can also be used as a means of promoting learning in extra-musical areas such as body awareness, mobility, communication, and social interaction (Ockelford \& Markou, 2012). In this literature review I will be outlining contemporary views and conceptions of disability, as well as some ways that the concept of participation may be understood, as perceived by commentators. Due to the setting of the current study, I will briefly describe the potential benefits of a transdisciplinary team approach to enhancing the learning and development of young people with disabilities in schools, followed by a review of past research studies in the area of music therapy and disability to indicate recent developments in the area.

The literature included in this review was gathered through a combination of online searches and physical searches in libraries for relevant book and journal material. Online database searches were conducted primarily through Scopus and Google Scholar, which in turn led me to online journal article libraries such as T and Francis, Wiley Online Library, Elsevier and Sage Journals Online. Manual searches were conducted mainly through Massey University library. Keywords and phrases utilised in the search for literature germane to this research topic included "special needs", "complex needs", "school”, "special education", "music", "music therapy", "participation", and various combinations of these examples.

In a systematic review of the use of music with young people with disabilities based in the US, it was concluded that this area is greatly under-researched, especially when considering the large numbers of music educators and therapists that work with this population (Brown \& Jellison, 2012). Several research studies conducted in the area of young people with special needs in community and educational settings have focused on the responses, engagement, communication and participation of young people with disabilities in various musical activities (Lee \& McFerran, 2012; Ockelford, Welch, Jewell-Gore, Cheng, Vogiatzoglou \& Himonides, 2011; Simeonsson Carlson, Huntington, McMillen \& Brent, 2001) and experienced music therapists have also shared their personal knowledge with regard to the strategies used to engage young people with special needs in musical activity (Hillman Boxill \& Chase, 2007; Wheeler, Shultis \& Polen, 2005). However, there is still a 
need to expand the number of researchers engaged in asking questions regarding how music is and can be used beneficially for the development and education of young people (Brown \& Jellison, 2012).

The concept of participation and health can be viewed primarily as an individual activity and state, or it can be seen as a socially-driven and influenced event whereby an individual's participation is interpreted with regard to interpersonal and social dynamics (Aldridge, 1996; Stige, 2006; Stige \& Aarø, 2012). For a young person ${ }^{5}$ with a disability, his or her ability to participate in communities and learn from those interactions will be affected by the prevailing attitudes and norms of society towards those with disabilities (Schwartz, 2008; United Nations, 2006). The extent of an individual's disability is constructed as a result of "complex interactions between a child's bodily or functional impairments and the barriers to learning and functioning which exist in the external world" (Lebeer, BirtaSzékely, Demeter, Bohács, Candeias, Sønnesyn, Partanen \& Dawson, 2012, p.85). Furthermore, the development of children with disabilities can be impaired when others do not expect them to achieve highly in tasks (World Health Organisation \& World Bank, 2001). The Convention on the Rights of Persons with Disabilities has attempted to address these existing obstacles to learning by officially encouraging the recognition of valued contributions made by people with disabilities to the wellbeing of their communities, as well as by promoting their full participation in society as it is understood this will "result in... significant advances in the human, social and economic development of society" (United Nations, 2006). Furthermore, whilst Ockelford (2008) claims that the labels of disability and special needs are valuable as they provide a "conceptual shorthand" that enables discussion on the subject so that progress can occur in the field, he also emphasises the need for all young people to be primarily recognised for their individual abilities, wishes and propensities (p.1).

\section{MUSIC AND DISABILITY}

Music therapy can facilitate and enhance learning for young people with disabilities, improve their communication, socialisation and physical skills, and promote their emotional wellbeing (Adamek, 2002; Jellison, 2000). Most contemporary music therapy has concentrated on eliciting clients' participation in direct communicative music-making to

\footnotetext{
${ }^{5}$ For the purposes of this study, this is used to refer to someone aged between 5-21 years.
} 
achieve beneficial results (Ansdell \& Pavlicevic, 2005), and indeed Lave and Wenger (1991) believe that the most fundamental form of learning occurs whilst participating in social structures.

In their pioneering music therapy work with children with intellectual and communicative disabilities, Nordoff and Robbins (1977) theorised that all children have a 'core musicality' that is innate and allows them to respond and communicate instinctively with another through the medium of music. Malloch and Trevarthen (2009) later took this idea a step further by claiming that all human communication is fundamentally musical, choosing the term 'communicative musicality' to describe the essence of most interactions between individuals.

It is important that music therapists respond to the abilities of those with physical and cognitive impairments by adapting their own behaviour and the environment such that any perceived limitations of the young person with disabilities are minimised, and possibilities for participation increased (Aldridge, 1996). Particularly with regard to young people with PMLDs, it may be extra difficult for others to interpret their behaviour if there are few observable or explicitly outward signs to indicate that they are participating in the same activity with the other person, which may affect motivation to continue a relationshipbuilding interaction (Porter, Ouvry, Morgan \& Downs, 2001). Moreover, even when physical movements and non-verbal vocalisations do occur, they are often such an imprecise method of communication that misunderstandings may occur "if workers assume a meaning from a certain idiosyncratic response that may not necessarily be in line with the feelings of the young person" (Ockelford, 2000, p.203). As such it can be challenging for professionals to accurately interpret the communication of a person with PMLDs (Lee \& McFerran, 2012).

\section{MUSIC AND PARTICIPATION}

Some contemporary theorists postulate that young children learn and experience the world primarily through independent thought and their own construction of life events, in addition to imitating and reflecting the actions of others in social situations (Aldridge, 1996; Lave \& Wenger, 1991). Extending this idea to musical perception, Elliot and Silverman (2012) contend that "sounds are 'musical' not simply because of their sonic characteristics, but because of the functions people assign them in specific social-cultural situations" (p.30). Participation may be viewed as a conscious or unconscious investment of self in - or contribution to - an activity that is shared with another person. Choosing to adopt the terms 
'operative intentionality' and 'act intentionality' as a framework, Merleau-Ponty (2011) differentiates between a more unconscious, instinctive connection with external events, and a conscious thought process through which we voluntarily take an action in response to a stimulus, respectively. It has been proposed that for young people with PMLDs there are two basic forms of response to sounds and music: 1) the unlearned and instinctive responses to the intrinsic qualities of sound, such as loudness/quietness, high/low pitches, fast/slow tempos, and 2) the learned responses created through the association of a piece of music with a particular event, activity, location, person, or feeling (Ockelford, 2000, p.202). The reality of sensing aurally, visually, kinesthetically and emotionally brings the person into the present and can have immediate results (Hillman Boxill \& Chase, 2007, p.8), creating a feeling of being musically, emotionally and intellectually "in-sync" with another human being (Taylor, C., 2008, p.37).

When discussing music therapy in the context of child development, Schwartz (2008) advanced a framework for practice to help guide those music therapists working with developing children, suggesting a hierarchy of stages that a child/young person must reach as they grow, which in order includes 1) Awareness, 2) Trust, 3) Independence, 4) Control, and 5) Responsibility. The first stage relates strongly to the previous statements about unconscious and conscious participation, and moving from a state of the former to the latter - which is usually deemed to be the desirable state for a client in therapy (Ansdell \& Pavlicevic, 2005; McFerran, 2012). Johnson (2002) suggests a similar four-step model of progression in musical participation, but with small differences to the above framework: 1) Exploration, 2) Control, 3) Independence, and 4) Function. Both Schwartz (2008) and Johnson (2002) describe in some detail what they mean by these stages in terms of the young person's musical and personal development, and they offer substantial practical and theoretical ways of understanding how it is that people can interact with and participate in music. As individuals in therapy progress to more advanced stages in these models, the assumption is that they will be assuming more control and power over their environment and relationships through intentional physical and communicative acts, as it is understood that such participation will help contribute to the development of more complex skills in areas such as memory, social, and fine motor (Hanser, 1987).

According to Littell, Alexander and Reynolds (2001), little is known about the link between client participation and various outcome measures in settings outside of health care and psychotherapy. However, Simeonsson et al. (2001) have claimed that research on 
participation in school activities suggests a correlation between higher rates of participation and positive outcomes in social and academic domains. As shown in studies investigating clients' participation in psychosocial treatment, often a client's participation has been assumed by practitioners and researchers solely on the basis that the person is present for the chosen intervention (Littell et al., 2001). However, this criterion cannot usually be applied to a population with very special needs, as often their physical and communicative impairments will restrict their choice to attend treatment sessions. Attempting to address aspects of participation so that findings can be applied generally, Littell et al. (2001) claim that participation can be interpreted through two dimensions from passive to active, and from negative to positive - while acknowledging that clients and clinicians may view the quantity and quality of activity levels differently.

\section{RECENT MUSIC RESEARCH IN SPECIAL NEEDS}

Music therapy is considered to contribute significantly to the education and development of students with special needs (Adamek \& Darrow, 2010; Ockelford, 2008; Patterson, 2003). In school settings, there exist two closely related musical disciplines: music education and music therapy. Although both strands can be understood to be mutually complementary, it has been postulated that music education's primary purpose is the promotion of musical skills and knowledge in their own right, whereas in music therapy the main goal is to promote a wider holistic development of students by facilitating the practice of important extramusical skills such as communication and motor control (Gallegos, 2006; Ockelford, 2008; Ockelford \& Markou, 2012; Welch et al., 2009).

The educationally situated research project 'Sounds of Intent' (Welch, Ockelford, Carter, Zimmermann \& Himonides, 2009) presents a developmental model of conceptualising how young people with PMLDs progress in areas such as communication, motor control and social skills through participation in musical activity. In this model, behaviours of students in music are interpreted in terms of three domains: reactivity, proactivity, and interactivity, with various levels of mastery outlined in each of these categories as a way of enabling an understanding of how young people with PMLDs develop in terms of their musical ability and non-musical goals (Welch et al., 2009). In a later phase of this research, it was contended that important factors influencing the perceived progress of students may have been partially due to "the young people's growing familiarity with the materials, [and] the routine of the sessions...which may have enabled them to engage musically more fully as 
time went on", as well as the music facilitator's deepening knowledge of those present in music (Ockelford et al., 2011, p.190). Lee and McFerran (2012) were interested to explore the area of offering song choice to people with PMLDs in music therapy, as this afforded the researchers a potential opportunity to learn about the preferences of participants, as well as allowing music therapy recipients to practise their communicative abilities. They found that participants were able to express song preference through increased and improved uses of intentional physical skills (e.g. vocalisation, facial expression, eye gaze) and affective responses (Lee \& McFerran, 2012).

People with PMLDs are perceived by some commentators as having a functional capacity similar to that of a two-year old child or younger (Coleman, 2002; Ockelford, 2008; Ware, 2003); however, there are clearly problems with applying this perception to an adolescent or young adult who has been in the world for many more years than an infant, and care must be taken to use age-appropriate activities when planning music therapy for students with such high complex needs (Adamek \& Darrow, 2010). While the person may be operating well below the typical level expected for someone of their chronological age, it is acknowledged that "some have markedly uneven profiles of development" (Ockelford, 2008, p.3), and thus may be understood to be significantly more capable in some areas than others. Furthermore, Simmons (2011) articulates in a case study research how a student's motivation to demonstrate his ability may be highly influenced by various environmental and situational factors, which could demonstrate a relatively sophisticated level of awareness and understanding of people and surroundings. Nonetheless, in light of the first statement, it seems pertinent to review Shoemark's doctoral study (2007) into the markers of interplay between a music therapist and a newborn infant for the current review. In her qualitative study, Shoemark found that infants - functioning at a very basic, instinctive level - presented themselves in three ways in response to musical activity: through a 'quiet interplay' (predominantly receptive and inactive), 'active interplay', and by physically and emotionally withdrawing their engagement to become 'not available' (2007). However, more relevant to the current research is her interpretation of her own part in musical interactions, where she viewed her musical behaviours as serving either an 'enticing', 'responsive', or 'directive' purpose with regard to her attempts at forming communicative pathways with the infant musical partner (2007). This applies to the current study as it is largely focused on the role the music therapist plays to facilitate and promote active participation in the musical relationship. 


\section{WORKING WITHIN A TRANSDISCIPLINARY SCHOOL TEAM}

Music therapists have the potential to support student learning and development by working in partnership with members of other professions such as educators, therapists from a number of areas, support staff, and families of students (Rickson, 2010). When working in a transdisciplinary team in a school for young people with special needs, therapeutic and educational workers collaborate and share knowledge in ways that may collectively contribute towards the student's learning objectives (Adamek \& Darrow, 2010). In music therapy, the practitioner can learn about a young person's abilities and skills through their participation in musical activities, although the skills may, in themselves, be non-musical - e.g. attention span, eye-contacting, grasping objects, turn-taking and choosing (Brunk \& Coleman, 2002; Coleman, 2002). Discussing with colleagues about a young person's abilities - or potential to improve in an area that may be relevant and meaningful for that person's wellbeing - may increase expectation among workers that the student will participate and succeed in certain challenges, thus partially eliminating the barrier towards achievement that low expectations can create (Adamek \& Darrow, 2010; Lebeer et al., 2012).

In a transdisciplinary model, the student is not seen in terms of perceived functional deficiencies, but as a whole person who is capable of participating within the school and wider community through the use of motor, cognitive, communicative, sensory and emotional skills (Johnson, 2002). In a study that investigated the effects of a music therapist educating school teams on how to implement and understand musical experiences for the promotion of student development, findings suggested that staff developed increasingly positive perceptions of student abilities as a result of utilising informed musical strategies for holistic student learning (Rickson, 2010). As well as interacting with students, professionals communicate and participate in each other's treatment implementation, exchanging information and thoughts on students as a means of increasing understanding about the student's learning styles and preferences (Johnson, 2002). Such staff co-operation and knowledge-sharing may better equip workers to be able to help the young person with special needs "listen better", which may result in the student's increased participation in learning activities (Lebeer et al., 2012, p.72). 
In this review I have outlined some factors that need to be taken into consideration for the implementation of music therapy practice with people with disabilities, whilst acknowledging that all people have the ability to communicate through musical means (Malloch and Trevarthen, 2009). Disability is now widely perceived to be a construct caused by interactions between personal and environmental factors, and society can work towards removing barriers to learning for people with disabilities. The literature indicates that participation can occur in a variety of ways, not just in the active form, and research has been conducted into the various kinds of behaviour people considered to be at a relatively early stage of development engage in while interacting in musical activities with others. A transdisciplinary team approach can help professionals to improve their knowledge of students, and this can assist in the raising of expectations for young people with special needs that may contribute to their overall development. These areas of interest will inform the rest of this study. 


\section{METHODOLOGY}

\section{PHILOSOPHY AND RESEARCH APPROACH}

A humanistic philosophy was at the heart of my work as a music therapy student in the school. I believe that every person has worth and a capacity for development towards selffulfilment, and that demonstrating an unconditional positive regard towards a person can encourage self-belief and ultimately aid the attainment of developmental goals (Rogers, 1995). To assist school students on the way to achieving these goals I aimed to be attuned to their needs and desires in the moment so as to foster a mutual understanding between us that recognised the validity and capabilities of those present during any activities.

The goal of this study was to understand what techniques and methods I used in the capacity of music therapy student to support the participation of young people with special needs in music therapy for their holistic learning, growth, and development. Such an exploratory investigation (involving 'what' and 'how' questions) implied a qualitative methodology, where rich description and a search for understanding of the foundations of practice are central (Patton, 2002). My clinical experience in the initial stages indicated that the responses of the young students in music and my behaviours for supporting them were complex, and so I felt that adopting a predictive focus at that early stage could have potentially limited meaningful findings (Marshall \& Rossman, 2010).

The overall purpose of the study was to create a meaningful contribution to the music therapy literature in the field of special needs, so that the quality of services for those with disabilities could be enhanced in years to come.

\section{METHOD OF INQUIRY}

I reviewed my work through a process known as secondary analysis of data. This method necessitates that the data being reviewed was originally generated for a purpose (in this case clinical documentation) other than the research question being investigated (Heaton, 2008). The data reviewed was compiled through the clinical and reflective documentation of regular case work in music therapy and attendant practices as part of the school team of teachers and therapists. True to the method of secondary analysis, once I established a research question following review of my practice the collected data was then re-used and interpreted through the lens of my new study. According to Thorne (1998) there are five ways that secondary analysis can be conducted; however because I generated my own data, 
the type of secondary analysis used in this study is understood by Thorne to be an "analytic expansion" (p.548). This is appropriate as I am conducting a secondary interpretation of my own data base to answer new questions (Thorne, 1998).

As this qualitative research was explorative in nature, there was a focus on theory-building as I gathered increasing data grounded in my personal experiences in and interpretations of music therapy sessions. Additionally, for this inquiry it seemed appropriate to adopt a hermeneutic approach, whereby I constantly reflected how it would be possible to "interpret the expressions of...clients in terms of their needs?" (Kenny, Jahn-Langenberg \& Loewy, 2005, p.335). It has been suggested that music therapists are forever involved in hermeneutic inquiry as they attempt to interpret and understand the actions and interactions of the people they serve (Kenny et al., 2005). It was always necessary for me to consider why I understood perceived events or behaviours in certain ways, in light of various influencing contexts and conditions. I am aware that any interpretations I made while experiencing music therapy sessions and analysing data were constructed solely in my mind (Patton, 2002) and that my attempts at trying to understand the possible thoughts and feelings experienced by students in music therapy sessions are only my best attempt at doing so. As such I do not claim that there is any certain 'truth' to what I propose in my findings, but the findings represent a genuine attempt on my part to understand students' participation in music therapy, taking into account my own pre-existing assumptions and attitudes.

In order to check and corroborate my interpretations, and to provide some balance to my own particular viewpoint, I discussed my analysis at various points with my clinical supervisor, student colleagues and research supervisor. I presented my emergent themes and codes to them, and sought their opinions about how they interpreted events from my practice as I had described them. They provided helpful feedback that assisted me in modifying and enhancing my approach.

\section{DATA COLLECTION AND SOURCES}

For this study it was important to collect data in a way that minimised the potential for altering the natural course of my music therapy practice. As Jellison (2000) notes, in order for music professionals to gain meaningful insight into their practice and the progress of their students, a skilful and sensitive use of observation and documentation procedures is crucial. The data collected was based upon my observations and experiences in music 
therapy sessions with school students. Sessions usually lasted between 20-30 minutes, and were predominantly one-to-one in private rooms. Following music therapy sessions, I wrote about my experiences in an electronic document, and recorded more general thoughts and feelings in a reflective journal. Often I found it easier to write my reflections in the same space as my clinical notes, however as time progressed I increasingly separated these data sources. I feel that the act of writing these reflective passages helped me to become more self-aware, and gain a deeper understanding of music therapy sessions through consideration of my own feelings and the possible feelings of students.

Other sources used in the recording of data that contributed to a growing awareness of my practice included the pre-existing school documents that pertained to the history, preferences and known abilities of the students with whom I worked. In addition, sometimes I recorded music therapy sessions with a camera, and afterwards reviewed the audiovisual material. Every student in the school had an online 'e-portfolio' to which updates on student progress were continuously added, and I sometimes contributed to the e-portfolio of students with whom I worked by uploading video segments on their profile, and writing descriptive comments underneath for family and staff members to review. Lastly, I accept that personal communications from other school staff about students I worked with also affected my practice to a degree, and I documented these interactions whenever possible.

\section{DATA ANALYSIS}

Whilst secondary analysis was the overall approach of inquiry, it does not by itself explain what precise methods I employed to review the data and attempt to find links, correlations and meaning therein. To organise my thinking with regard to reviewing the data, thematic analysis was thought to be the method of analysis best suited to the aims of this project. Following Braun and Clarke's (2006) flexible approach to thematic analysis, I used both inductive and deductive methods of data review. However, as the analysis process progressed and my awareness of my own actions increased, increasingly a deductive approach was employed as I - the inquirer - developed working hypotheses to explain the data (Schwandt, 2007) as past insights continued to shape my interpretation of future events.

The first stage of this analysis for me was to write down my feelings and thoughts about clinical notes in the form of analytic memos. This was done both on the original clinical 
documents, but also in other places where I could quickly record my thoughts if I was not near a computer. These analytic memos were found to be important for the formation of initial links and research ideas. The next stage of my thematic analysis involved 'coding' (Gibson \& Brown, 2009). For this study I adopted an approach of 'open coding', which is to say that I analysed with as open a mind as possible and did not base my initial coding on any pre-existing models of understanding (Gibbs, 2007). Through this approach I searched for key ideas from the data that appeared relevant to the research question. Although - as mentioned previously - my initial coding was primarily inductive in nature, I recognise that I may have been influenced to an extent by my knowledge of reviewed literature. The open coding method I adopted seems closely related to the 'analytic coding' as referred to by Richards (2009), who states that "this is the coding that leads to theory 'emergence' and theory affirmation" (p.96). A valuable way of ensuring that coding was applied consistently across the data was to define codes by describing the analytic idea - this was done to increase the reliability of the coding strategy (Gibbs, 2007).

After generating various codes, I began attempting to find broader links between them so that they could be grouped in overarching themes for clarity, ease, and quality of understanding. However, as Richards (2009) notes, it is always necessary to revisit and review the coded data in a way that allows the researcher to reconsider what codes and themes are suitable, too restrictive, or too broad for the purposes of understanding the research question. As such, sometimes separate codes were merged if they were found to be too closely related, or reconceptualised with broader titles and meanings if I found that the phenomena I perceived could be more suitably described in new ways.

As the majority of my sessions were with individuals in private settings, I decided that it would be best if I excluded group music therapy sessions from analysis so as to not overcomplicate the analysis process with issues of group dynamics. I considered that there were too many individual sessions to analyse within the time constraint of the research project, and so initially I limited the number of sessions to review to a total of 75 sessions spread out over my nine-month placement, and a total of nine students were amongst the people involved in these sessions, to varying extents. This represented approximately half of the individual music therapy sessions conducted with students. I projected that this would provide me with enough data to allow me to generate sufficient insight into the research question. I began reviewing the sessions approximately mid-way through my placement period, analysing sessions 1-30 first. Following this, after a break of 10 days, I then 
reviewed sessions 50-80, and to incorporate a later period of my work into the analysis I included sessions 110-125 for review also. When I began writing my findings and had established the themes and codes of the research, I then engaged somewhat in a process of 'optimal sampling', whereby I searched for data samples that seemed to be typical examples of the kinds of instances that I was trying to represent in the findings (Bruscia, 1995).

In the course of my analysis, there were what I consider to be 3-5 major turning points in how I viewed and interpreted the data, in collaboration with inputs from supervisors and colleagues. I created several different thematic models of understanding along the way, changing names of codes, themes, and changing codes between themes also as I continued to enhance my understanding of practice. This was based on my continuous testing of existing codes to see if they were applicable to various scenarios and student interactions. This process allowed me to be reasonably confident that my final conception was a well thought out and rationalised explanation as to how I attempted to support students' participation in music therapy.

\section{ETHICAL ISSUES}

On account of the secondary analysis approach taken and the fact that there were no direct participants involved in the study, this research was seen to be a relatively low-risk undertaking in terms of student and school rights, safety and security (NZSM, 2011). Nevertheless, there are some issues worth acknowledging here. Irrespective of the content and progress of my project, it was important for me to always ensure that music therapy treatment occurred in a naturalistic way, with the primary motivation for work to assist in the development and holistic wellbeing of the student. This would be consistent with the secondary analysis methodology which necessitates a retrospective review of accumulated data.

The right to anonymity and confidentiality for students, their relatives, and the school were upheld to the best of my ability as a researcher, as I was highly grateful for the privilege to interact and work with this school and its young people. Key information was de-identified when necessary so that students and others were not unwittingly and unwillingly exposed in situations where they would have rather remained anonymous. Furthermore, generated data that included information about music therapy sessions as well as specific people and events was kept safely and securely in locked compartments of the school, and on a password-protected computer when off the school site. Only those who had an ethical right 
to view such data had access under agreed circumstances. Such people or groups included certain staff members of the school, family members of those involved in the research paper, as well as current music therapy staff and students in the New Zealand School of Music.

Informed consent was sought and gained from those included and implicated in the research (see Appendices 3, 4, 6 and 7 for information and consent forms circulated to families and staff members). Maori culture and views were considered throughout the research, and meetings occurred with a Maori representative to ensure that respect was observed at all times.

The Massey University Human Ethics Committee granted approval for this research project to be undertaken under the generic template approved for NZSM 526 Casework and Research, July 11 (HEC: Southern A Application -11/41). 


\section{FINDINGS}

Following the review of various data sources, there emerged three distinct themes in my practice that allowed me to rationalise and understand what I was doing in music therapy sessions to help support the participation of students in music therapy. Although distinct, themes are not necessarily exclusive as it may be argued that some codes share qualities of other themes. Nevertheless, I feel that the manner in which I have organised codes and themes represents a valuable way for understanding the data for the purposes of this particular study.

In this study, student participation was found to be supported when a collaborative partnership was nurtured between myself and students, and when I found an ideal balance between following student behaviours and leading musical activity myself. When this balance was achieved, I felt that musical ownership and sense of accomplishment could be shared more equally between participants. Furthermore, based on the changing needs and engagement levels of students during sessions, I found that it was important to create what I have termed a 'dynamic flow' in order to maintain student arousal and interest at a high level so that student collaboration and participation could be sustained for longer.

In this section I will briefly address each of the inductively formulated themes in turn, during which I will provide a concise definition of themes and then elaborate on individual codes within them. To begin with however, I shall present a case vignette that I feel illustrates some important aspects of my practice as regards the methods and techniques I employed to support student participation in music therapy.

\section{CLINICAL VIGNETTE}

At the beginning of our music therapy sessions together in school, Mary-Jane ${ }^{6}$ was 20 years old. She was the oldest student there, and was beginning the process of transition to another social facility where she could continue to grow and learn. She had little control of her arms and legs, but seemed stronger with her right arm. She had no expressive language, however her ability to understand what others said appeared to be good, especially when it came to familiar names and words. Mary-Jane had a cortical visual impairment, meaning that she could see very little, if at all. Her teacher believed that she mainly understood the world around her using her hearing and touch cues. Most times when I saw Mary-Jane she

\footnotetext{
${ }^{6}$ Name changed.
} 
wore purple, or clothes with a predominantly purple design. I heard that this was thought to be Mary-Jane's favourite colour, which is interesting considering her reduced vision; however I never asked her about this. When Mary-Jane became interested or engaged in something, she often moved her head and eyes around.

At her birthday party, which I attended, her father recounted in a speech how until she was born, Mary-Jane's development was just like anyone else's; however, due to asphyxia at birth she acquired cerebral palsy which affected her development henceforth. She was nearly always in a wheelchair while at school, although like other students she would sometimes get a chance to swim, stand in a frame, and lie down for a rest and stretch. She had a cheeky, easy-going sense of humour, smiling when amused and laughing heartily when excited. I felt that Mary-Jane's ability to express emotion was extremely important to helping me learn about her, as it allowed us to create and share many happy moments together, helping our relationship to flourish.

It was soon to be our $11^{\text {th }}$ session together when I had made my way to Room 4 as usual to meet Mary-Jane in class so I could ask her to come to play music with me. She was dozing, looking sleepy with her eyes closed. Her teacher once told me how she felt that Mary-Jane's ability to complete a task depended partially on how tired or alert she was, and so I always kept this in mind so as not to be insensitive to her needs. I talked to her, preparing her for what was going to happen next. I wheeled Mary-Jane towards the hallway, and I noticed her eyes open as we left the classroom, probably because she felt the movement and heard me talking to her. Nearly every time I went to meet Mary-Jane in the classroom to wheel her to music, she changed from a state of stillness and apparent indifference to one of animation: looking around, moving her mouth and arms, eyes opening wider, and - importantly smiling. I always expressed my delight to Mary-Jane when she seemed happy, enthusiastically reflecting my genuinely excited feeling back to her in return. We began music by playing 'Mary-Jane' to the tune of 'Lollipop' as we had become used to doing in previous sessions. I recorded the familiar four-note vocal riff that follows the chorus onto Mary-Jane's switch and when I sang it she quickly released a knowing smile. With the switch balanced on her lap, she followed the sound of the guitar as I circled her. After I increased the intensity of my strumming to signal that it was nearly Mary-Jane's part at the end of a chorus, I sang "Mary-Jane, say hello", and tapped on her leg as I continued to hum. I noticed that Mary-Jane was moving her tongue and mouth increasingly, and after about 10 seconds of my gentle wordless music, Mary-Jane raised both of her arms to the switch. This was 
accompanied by a quiet vocalisation - I understood this as her way of saying hello. Grabbing hold of this rare opportunity to explore our voices together, I then helped to develop MaryJane's short rising melody by imitating her sound on top of a spacious one-chord interlude. When Mary-Jane became quieter, and then I resumed the song proper, she smiled. She always seemed to relish the beginnings of familiar songs.

Mary-Jane began the next song herself on keyboard, playing a note with the back of her left hand as I readied the keyboard for her. I joined her by improvising our very own 'congratulations' song. It was bright and bouncy because that is how I think we both felt, and Mary-Jane smiled at the fun of it before raising both hands back up to the keys, showing even more joy on her face as I backed her up. When Mary-Jane's arms dropped for a period, I substituted the title word for "can Mary-Jane play?", after which her mouth action increased noticeably. By the end of the verse she had both hands playing on the keys again, encouraged by our song. Mary-Jane and I then left the usual song pattern, replacing it with an airy and light melodic improvisation; in it Mary-Jane would begin the line by playing a note, I would use that as inspiration to develop the phrase. Mary-Jane laughed when I did this, and because she kept her hand on the keys she played a note herself whenever I stopped. This purely instrumental period lasted for almost two minutes, and a serene sense of calm and creativity filled the room. When we finished the piece and Mary-Jane had stopped moving for a while, I felt it right to play a tune independently with a simple, almost childlike character. Mary-Jane was captured by laughter for the next few breaths. It is impossible to know what made her laugh, but it is clear that there was something in what I did and how I did it that connected with Mary-Jane in that moment. The absence of sung or spoken word may have left the space open for her own independent thoughts and reactions to what my music could mean.

After another round of 'congratulations', we moved on to the grand finale of our music sessions together: 'too strong'7. Since its inception in our third session together, it had been my - and I think Mary-Jane's - favourite activity. It was born after Mary-Jane had almost knocked the chimes to the ground, accidentally, and without thinking I started singing our new upbeat song. After sitting quietly during my chordal introduction this session, MaryJane burst into a wide and animated smile when I started singing that energetic melody, recognising the song and what it held in store. She participated and laughed regularly, appearing to become re-energised every time I changed my playing style suddenly from

\footnotetext{
${ }^{7}$ See Appendix 8 for notation of this song.
} 
loud to quiet, fast to slow. In later sessions we would develop our song even further as we began taking turns playing the chimes - "now Conor's gonna play the chimes (jingles, waiting for sound to fade)...and Mary-Jane's gonna play the chimes...”. Mary-Jane nearly always became incapacitated with laughter when I began this sequence, and she had to come down from her high in order to play her part. I loved watching her laugh and felt in no rush to hurry on, but waited for her to play the chimes, and own her song. I also learned that she liked it when I danced in a circle around her when playing energetically; she would follow the sound with her head wherever I went, smiling with her eyes. Mary-Jane would most often play when strong cadences were presented, and when I emphasised leading words at a slower speed. I sang "she can knock-them-to-the...", and Mary-Jane lifted her arms to the chimes and so I acknowledged this by finishing the line with "...ground, ohhh". She also laughed, sang, and contributed in other spontaneous ways that always helped to shape my music. I felt this song was the creative culmination and embodiment of our relationship together, bringing a uniqueness that gave it extra meaning and value, as well as a shared knowledge and feeling between myself and Mary-Jane that this was special to us. Mary-Jane's name was the central lyric in the song from the very first time I improvised it in direct response to her actions, and maybe this made the song feel more like it 'belonged' to her.

In our twenty-second and last session together, I suggested that we play a song on the keyboard, but that Mary-Jane could start "when she liked". Although in the past I had always tried to follow Mary-Jane's contributions, I had never stated this so explicitly before - I wanted her to be sure that she was in control and lead the way. I sat back quietly, and was prepared to keep doing so for a time even if Mary-Jane chose not to play. However, within a few seconds Mary-Jane had raised both her arms to the keys to play, and I happily joined in with her. Whenever I stopped, Mary-Jane made sure to keep the music going. We didn't get to play 'too strong' today, as Mary-Jane's teacher had rung the bell for assembly in order to gather everyone for my farewell. At first I thought this was a shame, however it felt like a poignant end as I wheeled Mary-Jane in with me to the assembly and stood beside her as I listened to everyone's farewell speeches, gave my own speech, and sang a special goodbye song for everyone in the school. 
The following model illustrates the three main themes of the research:

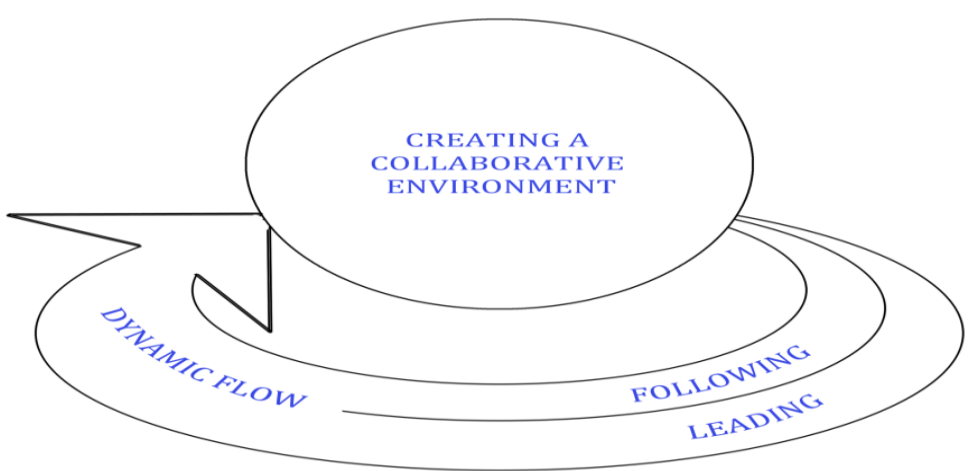

Figure 1: Supporting Participation Themes

\section{CREATING A COLLABORATIVE ENVIRONMENT}

The title of this theme changed numerous times throughout the research as my understanding of it became more complex, with one such former name being 'Empowering'. However I felt that the title finally chosen represented an attitude and ethos more based upon equality and respect between myself and students in music therapy. Here is my understanding of this theme:

To create a collaborative environment, I must do all I can to help students feel safe and informed; I must keep in contact with them; and I must do all I can to share control with them through creating opportunities for them to get involved in thinking and acting.

There are six parts that make up this theme, and I shall now discuss each of them.

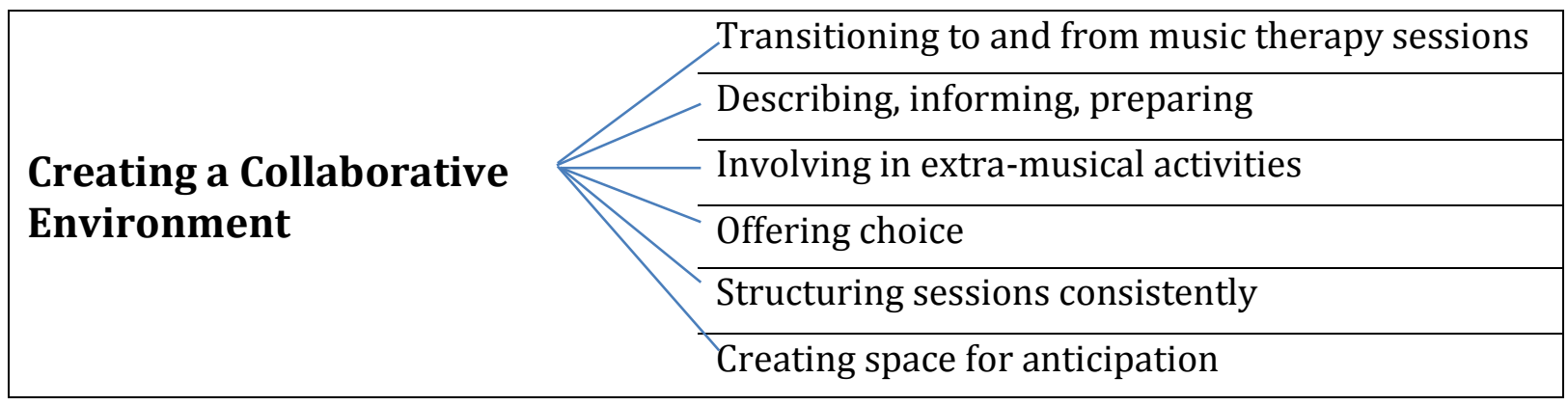

Figure 2: Theme One Codes 


\section{TRANSITIONING TO AND FROM MUSIC THERAPY SESSIONS}

This involves the space of time that can be used to support the transition of students into a new environment and help them to feel comfortable within it. Interactions that occur in this pre and post session time can strengthen the therapist-student relationship.

Individual music therapy sessions invariably took place in a private room outside of the classroom. Sometimes a teacher or teacher aide brought students to the room in which we would have our session, and other times I would collect them from the classroom myself. Much of the time, the determining factor for who transferred students from class to the music therapy room was how organised and prepared I had been with regards to room setup and session planning. My reflective and clinical notes indicate that as my experience, knowledge (of the workplace and students), and time management skills increased, so too did my ability to meet students in their environment prior to sessions, and bring them with me to music therapy. Based on my experiences and reflections, this process of actively assisting in the transition of students to music therapy seemed to allow for a number of important initial interactions in a 'neutral' environment between myself and students.

Firstly, I documented many times the animated reactions of different students as they saw me approach with my guitar, with vocalising, vigorous arm movement, and smiling being common responses as we made eye contact in the classroom. As the vignette illustrates, for students with visual impairments, the first thing I usually did was to say hello and ask if they wanted to come play music with me. This would present students with an opportunity to express themselves as others did in anticipation for what was expected to happen.

Furthermore, my clinical notes show how on several occasions the transition period was a time for the initial improvised interactions between myself and students. They demonstrate that improvisations could be initiated by either of us, and often grew out of our mutually imitative vocalisations, or playing rhythmically to footsteps of students (in the case of the more physically able). In addition, the facial expression of students often provided an impetus for me to respond verbally or musically in appropriate ways that for me reflected their perceived happiness.

\section{DESCRIBING, INFORMING, PREPARING}

The process by which the therapist articulates and explains when change is about to occur in the attempt to help students become more aware of their surroundings, as 
well as to help them understand what is happening and why.

Most students in this study had little or no capacity to communicate verbally with others (with a couple of exceptions), thus limiting their ability to ask questions or have a level of influence on my actions through clearly expressed desires. Because some also had severely impaired vision, I found that it was important for me to narrate for students what was happening, where I was going with them, and why. I wrote in clinical notes and reflective passages that I felt this process could have been good for preparing the student for events, allowing them to anticipate musical activities and potentially reducing any discomfort or anxiety caused by a sudden or unexpected change of environment or personnel.

Particularly for students with impaired vision and more profound physical disabilities, such as T and Mary-Jane, I often told them when I was moving certain instruments towards or away from them. This information possibly supported them to take control through managing themselves (a key competency) within changing environments, and specifically allowed for T and Mary-Jane to respond to information in appropriate ways by spontaneously lifting their arms from the keyboard as a way of assisting me in the movement of instruments.

Finally, the data shows that throughout my placement I increasingly came to appreciate the traditionally accepted 'goodbye song' at the end of sessions as a way of informing and preparing students for the end of sessions and the changes associated with it. However, I did not come to understand 'hello' songs in the same way, as the beginning of music therapy sessions could possibly be signalled by a number of other behaviours and interactions prior to entry to the music therapy room, such as what often occurred during transition periods.

\section{INVOLVING IN EXTRA-MUSICAL ACTIVITIES}

This involves the therapist seeking opportunities for interaction and student learning throughout the period of meeting between therapist and student by inviting and encouraging students to contribute to practical and goal-orientated tasks.

The data showed that in transitions to music therapy and my facilitation of playful musical interactions once arrived, there were found to be many latent opportunities for student participation in ways that took power from me, and gave it to them. For example, on May 
$15^{\text {th }}$ I began a routine with $\mathrm{Z}$ whereby I would invite him to help me open the doors on the way to music by saying "open ...[pausing]", and completing the phrase "open sesame!" once $\mathrm{Z}$ raised his arm (as I had modelled), or vocalised. Especially in the latter half of my placement, I often invited $\mathrm{Z}$ and Mary-Jane to point the way to music for me in the hallway. In addition, my clinical notes show that on numerous occasions I invited students $\mathrm{P}, \mathrm{T}$ and $\mathrm{Z}$ to turn off the electronic keyboard by the button on the left side once we had finished with the instrument, to which all invariably responded by mobilising their left arm towards the button.

I felt that providing opportunities such as these for students allowed me to devolve some responsibility to them, giving them chances to express themselves as well as to practise important functional and communicative skills towards mutually agreed and understood goals.

\section{OFFERING CHOICE}

This comprises offering students time and opportunities to communicate preferences between objects and activities, so that their motivation to participate may be enhanced and input valued.

In the IEPs of certain students, a specified goal would sometimes be that they would learn to make intentional choices between two objects or activities. My clinical notes demonstrated that I attempted to afford a choice to students in several ways. The most common way for me to invite students to participate in decision-making was to present them with two instruments, often with one to the left and one to the right. For one student $\mathrm{T}$, such an opportunity seemed to provide motivation for her to look deliberately at the different instruments, after which she would usually begin to slowly mobilise her arm towards the instrument of choice. Such processes could often take 1-2 minutes, and so sometimes required myself and anybody else present to remain very patient and supportive of the student. Staff member E advised me not speak after the choice availability was presented to $\mathrm{T}$, as she felt that this would possibly pressurise and distract $\mathrm{T}$ in her attempts at communicating a decision. On reflection, I agreed with this approach in general if I felt that students had demonstrated an awareness of the options available to them.

Data analysis of clinical notes and the reflective journal shows that as I progressed in my practice, I increasingly began to offer choices to all students with whom I worked. The 
reason for this was because although 'making choices' was not explicitly a goal for all students (as some were assumed to have demonstrated the ability at an earlier stage), still I recognised the value of providing opportunities to students to express their preferences and practise decision-making skills in the hope that this could help them to feel like a person whose contributions I valued, whose decisions I respected, and whose abilities I recognised.

\section{STRUCTURING SESSIONS CONSISTENTLY}

The process of reviewing and evaluating sessions to discover the extent to which activities are felt to be beneficial for students, and re-creating the most useful ones so that students can utilise previous experience and knowledge based on those activities to help their participation grow.

In planning for and implementing music therapy sessions, I found that it was very useful and necessary to review previous sessions, with particular attention given to the most recent meeting (sessions were usually one week apart). This was done primarily through the reading of clinical notes, and sometimes by watching video clips of a recorded session, if available. I felt that this process of review allowed me to recognise and remember what activities or behaviours seemed to have elicited communicative responses from students or engaged them in active participation.

The perceived benefits of this approach were two-fold. Firstly, from my perspective, the preparation time involved in planning for sessions was significantly reduced whenever specific activities were understood by me to have been particularly beneficial for students' motivation to communicate and participate, based on their past behaviours. Once student participation was observed in particular activities and a greater familiarity with them established, we were able to experiment further within the known frameworks, and expand the number of ways students could contribute and learn through the activities.

Secondly, with the introduction and subsequent repetition of materials in music therapy sessions, students demonstrated a growing readiness for participation in them, as well as what were often interpreted by me to be responses of happiness through basic communicative means such as facial expressions and laughter. Several instances of this kind of behaviour following the introduction of a routinely performed activity in music therapy were observed with Mary-Jane (see vignette) as sessions progressed. In addition, as well as 
participating spontaneously in songs through vocalising and moving, Mary-Jane demonstrated a growing awareness of when she was expected by me to play at certain parts of songs by mobilising just prior to the points at which I usually slowed and paused to invite her participation.

\author{
CREATING SPACE FOR ANTICIPATION \\ Providing an opportunity for students to think or communicate about their \\ expectations and associations with musical cues, thus potentially increasing their \\ sense of control in sessions.
}

As mentioned above, I found that music therapy sessions with particular students gradually took on their own unique format which developed through our mutual enjoyment of musical activities. With the development of such routines, I then began to vary how I introduced material to sessions in such a way so that students could anticipate what might happen next and express their feelings about this. Without telling students exactly what was going to happen next, I would begin to play chords - often gently and freely - that resembled closely the rhythmic and harmonic qualities of a song played together many times previously. This process can be seen in the vignette, when after some time spent listening Mary-Jane reacted spontaneously to my chordal introduction of a familiar song, in turn prompting my musical response. I feel that the space created provided an opportunity for Mary-Jane to express herself independently and initiate interaction.

Another technique I developed to encourage students to think about what might happen based on past experiences and knowledge of music therapy sessions was to hold the first word of a song for a long time to see if the student could recognise the start and communicate their anticipation through vocalising or mobilising (like with D on June $25^{\text {th }}$ ).

\title{
FOLLOWING AND LEADING
}

This theme brings together two closely related features that occurred in all music therapy sessions. Throughout the course of my research I wavered several times between creating two distinct themes for 'following' and 'leading', and merging them into one broader theme that recognised the close relation of these two features, but also each one's importance in their own right. Ultimately, because following and leading can be said to be 
occurring simultaneously between participants, I found that addressing them together was the most suitable way to approach their analysis and description for this research project. Furthermore, as interpretations may vary with regard to who is following or leading an activity at any given moment, I considered it appropriate to recognise this disparity by grouping them together in a joint theme. The following definition represents my understanding of what the theme of 'following and leading' means in this study:

When I alter my way of playing in response to movements and contributions of students, and when I create music in reflection of how students present in music - their level of activity and perceived mood - I am following the student. When I initiate musical activities and interactions based on my own desire to create a framework of supportive participation for the student, or to invite or challenge the student in some way to communicate or contribute through music that is more a reflection of myself, I am leading the student.

There are a total of 12 codes within this amalgamated theme, as seen in Figure 3. A majority of them are recognised as either a technique or strategy of following or leading, with a few designated to a common area as they are understood to consist of elements from both concepts:

\begin{tabular}{|l|l|l|}
\hline \multicolumn{2}{|c|}{ Following } & \multicolumn{2}{|l|}{ Leading } \\
\hline & & Using repetition \\
Developing sounds & $\begin{array}{l}\text { Slowing and } \\
\text { Pausing }\end{array}$ & Using pre-composed songs \\
Not using words & $\begin{array}{l}\text { Using contrasting } \\
\text { musical elements }\end{array}$ & $\begin{array}{l}\text { Challenging } \\
\text { Playing without expectations }\end{array}$ \\
Responding to movements & $\begin{array}{l}\text { Creating a 'contact } \\
\text { song' }\end{array}$ & $\begin{array}{l}\text { Using 're-engaging' } \\
\text { methods and techniques }\end{array}$ \\
\hline
\end{tabular}

Figure 3: Theme Two Codes 
DEVELOPING SOUNDS

This comprises musically acknowledging the contributions of students in ways that build upon their input and value the importance of their active participation in activities.

One of the most frequent techniques I used in sessions was to imitate and elaborate upon the various sounds that students made while in music therapy. My understanding was that by repeating closely or building upon the vocal or instrumental contributions of students, it provided them with an opportunity to hear their contributions being acknowledged and valued by another person. Once such a sound interchange connection was established between myself and students, it often resulted in further sustained active participation and expression of students. The vignette illustrates my use of this technique (June $19^{\text {th }}$ ) as MaryJane and I developed an improvised dialogue out of our song 'congratulations'. On that day I wrote the following in my clinical notes:

At one point, Mary-Jane stayed on the same note for about 40 seconds, playing it about seven times at quite regular intervals as I played short passages in between that invited resolution through Mary-Jane's note.

I felt that my playing - elaborating upon what Mary-Jane had played - motivated further participation in this instance from her on the keyboard. When she had taken her hand down from the keyboard, I took more of a leading role once more.

I often developed the sounds of students on keyboard by playing notes near to theirs, as could be seen in my work with $\mathrm{T}$ (November $21^{\text {st }}$ ). It seemed to me that student reactions to this approach were sometimes quite animated, often appearing to motivate them to maintain their active participation. I reflected that a reason for this might be that because my notes developed close to theirs, they could possibly sense more clearly the connectedness of our music-making.

\section{NOT USING WORDS}

This involves singing or playing music with students without lyrical accompaniment or verbal support. 
In my work it seemed that I was inclined to sing words or speak a lot when engaged in improvised activities or songs with students. However, most of the students with whom I worked could not express themselves in spoken words, although there were many signs from them to indicate that they understood quite well the meaning of what others said to them. I noted in my reflections that this apparent proclivity to use words seemed to have been driven by a number of factors, including my urge to "fill up space" as a way of helping me feel more comfortable with students; to try to provide direction and a clear structure for them; and in order to narrate what was occurring in a particular activity for clarity.

However, gradually I came to realise that it was not necessary for these things to happen all the time. I increasingly played for periods of time without singing, and when I sang it was often a non-verbal sound that imitated closely the vocal expressions of particular nonverbal students. I found this form of vocal interacting to be helpful on a couple of levels in sessions. I felt this approach allowed me to accept and share in students' vocal abilities, and for one student $S$ especially it seemed that she responded well and was more likely to vocalise herself if I initiated interaction by playfully copying her repertoire of vocal sounds. Furthermore, another good reason for not using words in music or singing was that it freed up some cognitive space in my mind, allowing me to dedicate more attention to the actions and behaviours of students and become more attuned to their needs. Consequently, I found that I could more often follow students in their actions and expressions.

\section{PLAYING WITHOUT EXPECTATIONS}

This involves providing a safe environment so that the therapist can be ready to devote specific attention to supporting the present needs and expressions of students rather than prescribing goals and creating expectations that students will respond in any particular way.

Because all students had specific goals that the school and their families wished them to work towards, I always had planned several activities that I could use that linked to these goals in sessions if it felt appropriate. In addition to the stipulations of the IEP, I also kept in mind the value of supporting socially valued behaviour such as turn-taking and making eye contact. With all of these things to keep in mind for sessions, I found that sometimes my view of various behaviours, student needs, and how I could help to provide opportunities for participation could be restricted. As such, and particularly in the early stages of my placement, it seemed that sometimes I persisted too long with certain activities in sessions 
in the hope of encouraging a specific type of participation even if the student was clearly not yet receptive to engaging in such a way.

I felt that sometimes these kinds of interactions were characterised by me taking an excessively leading role, with the student seeming either disinterested, unmotivated, or unreceptive to my invitations or challenges. When an event like this occurred, it felt frustrating for me, leaving me low on ideas for how to re-engage students for their learning development. To regroup and 'centre' myself, I sometimes sat quietly or began playing chords on guitar without focus on the student, whilst still providing them with an opportunity to respond and participate in the music. In such instances I was primarily trying to 'hold' the student so that they felt comfortable in the room, and also to regulate any existing feelings of frustration within me.

I found this strategy to be useful in my work with $\mathrm{P}$, who was known to have difficulty managing his anxieties. In a session on October $29^{\text {th }}, \mathrm{P}$ had sat by the door with his hand sometimes on the handle as I sang what was meant to be an inviting introductory song. Hoping to hold him in the room, I decided to follow P's vocal expressions of unwillingness to play ("uh uh") and incorporate them through imitation into a slow and calm three-chord song that only used his sound. After about 1-2 minutes of this, P accepted an invitation to pick up the second guitar in the room. Here he seemed to benefit from the opportunity to express his feelings freely and initiate interactions without invitation from me.

\section{RESPONDING TO MOVEMENTS}

This involves the therapist acknowledging and responding to specific movements in a way that recognises the context and importance of the student's possible expression. This is because physical movements are potentially an important form of communication, especially in the absence of speech.

In addition to perhaps the clearest sign of student engagement - active participation - I also looked out for physical clues that may have indicated how involved students were in musical activities. Particularly when playing music with the more profoundly disabled students who had very restricted physical and vocal capabilities, it became extra important for me to be very observant of any changes in how they presented when in music therapy, and reflect those changes in my music so that I could do my best to incorporate them in the musical activity. For example when I offered D a ball to hold in a session on April $2^{\text {nd }}$, even 
though he did not successfully grasp the ball I responded musically to his small hand movements that indicated to me that he may have been attempting to participate in his own way.

If for a while in sessions no clear or strong direct participation by the student was forthcoming, and suddenly I saw a small change of head direction, a smile, or minute movement of the arm, I sometimes incorporated these aspects of the student's presentation into my lyrics, sometimes coupling this with an appropriate change of tempo, rhythm or dynamics to emphasise that I accepted and valued them as they were.

USING REPETITION

This comprises creating opportunities for student participation through continued exposure to various music or activities for which the student has shown a tolerance or liking. The therapist also acknowledges student contribution to a particular passage by repeating it as a form of celebration and chance to confirm the reason behind a specific moment of participation.

The use of repetition in music was a central element of my practice. Given its apparent prevalence and somewhat naturally occurring presence in my work, during analysis I wondered if it justified being a code in itself or if it should simply be assumed that it happened a large proportion of the time in music therapy sessions. However, ongoing analysis of my clinical and reflective notes seemed to reveal that musical repetition served a number of purposes in activities. To begin with, I reflected that by repeating musical passages, melodies, and rhythms to students an opportunity could be afforded them to become more familiar and feel increasingly able to participate within a consistent musical framework. This reason for employing repetition appeared to be evidenced in a large majority of sessions.

Secondly, when students responded or participated through facial expression or movement to a particular musical passage, this often made me want to repeat an identical or similar action shortly afterward to see if another like response could be elicited. More broadly, the data showed that I was usually more likely to repeat a certain activity if the student had displayed a clear level of engagement in it, and in this way it was hoped that student 
enjoyment and successes could be promoted and repeated within an activity for which they seemed to have expressed a preference.

\section{PRE-COMPOSED SONGS}

This involves the use of songs previously known to the therapist in sessions, with songs often transforming lyrically and musically based on the responses and needs of students.

The utilisation of a repertoire of pre-learned material was found to be another far-reaching part of my work in the school. Songs were my preferred way of interacting with students, more than pre-composed instrumental material without vocal lines. In the course of formulating codes for this research, there were many changes, contractions, and reconceptualisations of the significance of various musical tools employed when playing pre-composed songs. Such tools included adapting words to suit a particular situation, and even more specifically 'naming' students in songs, inserting their names in lyrics as I sang about them to reflect, affirm and invite various ways of being and doing.

The decision to use pre-composed material in music was also found to be helpful in my planning of sessions. The reason for this was that as the general melodic, harmonic and rhythmic elements of activities were largely decided, this allowed me to be able to adapt and stretch the musical potential of songs in whatever ways I felt best suited the needs of students at a particular time, while still keeping the familiar musical boundaries within which actions were framed. However, in discussions with Ann following some sessions in which we both were present, she reflected that sometimes it could have been useful to follow students more in their actions if they seemed to be communicating something important, instead of following the song structure. Reflecting on some sessions together, we also agreed that on some occasions students did not seem to be engaged by particular songs, in which cases we, Ann and I, felt it was important to take into account the expressions of students and change strategy to support their participation.

Lastly, the data showed that as I progressed throughout the year I increasingly used songs that I considered contemporary to students, and appropriate to their age bracket, instead of traditional 'children's songs'. Some of the young people with whom I worked were between 13-21 years old, and so I felt that they deserved to be treated as such. In an individual music therapy session with T on August 15th, I introduced my lyrically adapted version of the pop 
song 'Valerie' (changed to the student's name). It was noted by both myself and staff member $\mathrm{E}$ (who accompanied $\mathrm{T}$ and I in several sessions) that $\mathrm{T}$ seemed particularly responsive and expressive when we played this song, and E suggested that it may have been because it was T's music of choice and "the kind of thing she listens to at home".

\section{CHALLENGING}

This involves implicitly and explicitly inviting students to engage in a certain form of achievable participation at appropriate moments that supports their interaction and learning.

A technique I often used to engage students in a particular form of participation in music was to try to draw their attention towards a certain instrument or part of their body that they could use. I usually communicated this through gesture or voice, sometimes by singing their name along with what they "can" do, or by asking a question. Examples of these techniques of challenging to invite student participation could be seen in a session I had with $\mathrm{K}$ on April $2^{\text {nd. }}$ In one activity $\mathrm{K}$ seemed to not strike the drum spontaneously himself whenever it was placed between us; however, as I leaned the drum towards K to indicate it was his turn every so often, he played most times I offered it. In the same session when I improvised a song, at regular rest points I sang the question "what will K say?". Whenever I sang this challenge, after about 6-10 seconds of waiting K consistently responded with a soft grunt, whereas before he did not seem to actively participate in any obvious way.

Although challenging students implicitly and explicitly seemed to be an important means of instigating interaction between us, in my reflective journal I also noted that it seemed equally as important to avoid challenging students excessively. In relation to a session held with T, I commented to E that "it's tough work playing all the time!", as I had become conscious of the fact that I may have been requesting too much of $\mathrm{T}$ in the way of active participation through singing and movement.

An example of the benefits of considering a variety of cues from students in addition to active participation when they are being 'challenged' can be seen in the following segment taken from my clinical notes written on September $3^{\text {rd }}$ after a session with S:

I started improvising a short song, and repeated it many times...It had two sections...At the end of phrases in the first section I played the tambourine twice quickly. Early on for the first few rounds of the song, I played and sang myself, whilst pausing and slowing for $S$ at different points to invite her to 
play... Even when not playing, S appeared happy as she smiled a lot and vocalised in her usual way (e.g. "gaga"). After about 4-5 rounds, I offered $S$ the tambourine by holding it out at the times when I usually played it myself in the song. After she struck it a few times at these points, I then invited her to hold the tambourine, and she accepted.

\section{PHYSICALLY SUPPORTING}

This involves supporting and guiding students towards potential ways of participating - often by assisting the movement of hands and arms - while also being sensitive to their responses and receptiveness towards such actions.

Making physical contact with students in music therapy was a technique that served an important function in some sessions. The most common reason for this contact appeared to be to support students in becoming active in music-making or dance. However, sometimes I also made contact with students (e.g. holding their hand) to express that I valued and accepted them as they were, without any other motive.

Conversations I had with staff members D and E helped to increase my awareness that it was sometimes beneficial to wait a while in order to allow students accomplish tasks in their own time, as it was thought that due to their condition, their physical responses to music could be somewhat delayed. I invariably allowed students opportunities to participate independently in activities at first. However if I had witnessed little in the way of active movement for some time, particularly from those with profound gross motor impairments, I would often then physically assist them in a gentle manner to move or make contact with an instrument. I hoped that this experience would encourage them to independently engage more actively in activities. For instance, in sessions with Mary-Jane, I found that if I helped to raise her stronger arm in a rhythmically pulsating way when I played, then she usually "took over" the movement by continuing to mobilise herself without my assistance towards the instrument (as noted on June $12^{\text {th }}$ and several times afterwards). I hoped that the rhythmic and gentle nature of the physical support meant that the assistance could also seem enjoyable in itself for students, and not appear like I only wanted them to complete a task that they didn't necessarily agree to.

As well as helping students to experience movement on the way to independently playing instruments if they so chose, the clinical notes illustrated that there were two more recurring reasons for which I physically supported students; one of these was to 'dance' together with students using rhythmic arm movements; the other was to assist those with 
fine motor impairments to take hold or grasp musical implements or small instruments, as for example happened with $\mathrm{T}$ and the xylophone mallet in several sessions, and $\mathrm{D}$ with the egg shaker.

\section{USING RE-ENGAGING METHODS AND TECHNIQUES}

In the event that a student appears to become disengaged in a session, the therapist can revert to an activity for which the student has displayed a strong liking in past sessions in the attempt to re-engage the student in some form of interaction.

After several sessions with students, I generally began to develop an understanding of what kinds of activities, instruments, songs and interactions they typically enjoyed. If there was a period in a session where I felt that the student had become less engaged in an activity, I used this knowledge in the hope that they would either react in some way to my action, or become actively participative.

For one student Z, my re-engaging technique (which I learned from a chance playful interaction when I stopped to think about what to do next) was to stop and look away as if into the distance with a 'thinking' face, which almost always succeeded in eliciting a vocal and physical response from Z. For Mary-Jane I found that one of the best ways to re-engage her was to play songs for which she had expressed a strong liking in the past. Sometimes the choice of instrument appeared to be the key to re-engaging students in interactive participation, as seemed to be the case with A, who often spontaneously chose to play the guitar or drum without direction from anyone else. In the case of $\mathrm{K}$ - who often seemed tactilely defensive, throwing and pushing objects away - my experience with him in music therapy indicated interestingly that perhaps the best technique to re-engage him if he appeared 'un-cooperative' was to sit down opposite him and sing our 'hand-holding' song, which I had improvised in one of our earlier sessions together. When I did this, K's eye contact, attentiveness and responsiveness invariably improved.

The data appeared to indicate that once contact was re-affirmed with students via reengaging strategies and techniques such as the ones stated above, further opportunities for interactions could then be created as the student became more attentive towards me. 


\section{SLOWING AND PAUSING}

This involves signposting moments when students are invited to participate through a temporary decrease in tempo and creating an inviting space for contribution, often at the ends of phrases and cadences in musical activities.

When playing in an activity I commonly employed the technique of noticeably decreasing the tempo in a short space of time towards a cadence point so as to do my best to indicate to students musically that there was an available space in which they could play. In an early supervision meeting with Ann, she suggested that in her experience it was sometimes helpful to hold the dominant chord while pausing at the cadence point so as to invite students musically to participate. I felt it was important that students could have time to familiarise themselves with melodic and rhythmic structures through repetition so that if they chose to play, their contribution could have more meaning in the context of a known musical activity; and I also imagined they may have been more motivated to play in a piece where they could know what had to be finished!

One recorded example of this technique in action was with S (October $24^{\text {th }}$ ) as we shared the xylophone together. I sang a goodbye song ("we'll say goodbye now to S)", and both of us held one mallet. I played and sang the same notes, and when I paused briefly on the first syllable of her name at the end of the fifth repetition, $S$ then enthusiastically played for the first time on the final note. I feel this example demonstrates well the two ways that I invited students to participate through the slowing and pausing technique - through lyrical and/or melodic leading.

It was important to consider when and how to invite students to participate in these kinds of ways, as well as for how long to wait for students' input. I tried to follow students and use their signals as clues about how ready they might be to actively participate at different times. By judging carefully the timing and framing of invitations I tried to maximise 'success' rates for students so as to help enhance their self-esteem and positive associations with activities - they could not be expected to respond every time I invited them especially if they did not appear to be in the mood. Even as I waited for students' contributions by remaining predominantly on the dominant chord, I increasingly developed an appreciation for keeping my music dynamic and supportive through the use of rhythmic and vocal 
variations. I also had to know when to 'move on' and accept it if the student chose not to participate.

If students knew a song well enough and the places where I traditionally slowed to invite their participation, I sometimes found that gradually they would begin playing spontaneously at the usual invitation points without me having to obviously slow as I had done earlier. This could be seen in a video recorded session with P (November $19^{\text {th }}$ ) where we sang alternating vocal lines without me having to prompt him as I had done earlier. I later reflected that as a result of this kind of participation students appeared to demonstrate a greater level of independence and understanding of our relationship.

\section{USING CONTRASTING MUSICAL ELEMENTS}

This involves playing musical pieces in a variety of ways that explore the richness of the musical possibility (e.g. in terms of texture, tempo, and dynamics), thus providing an array of different experiences for students to help keep them engaged and interested in therapeutic interaction.

As I became more experienced and resourceful in my execution of activities in music therapy, I increasingly began to take into consideration the many rhythmic, dynamic, melodic, harmonic, instrumental and tempo variations that I felt could help develop activities and keep them engaging for students. When I began the data analysis process, it soon became clear to me that the exploitation of musical elements such as the ones mentioned above often seemed to be an important factor influencing the positive development of sessions and individual activities. The reactions of students in response to changes in my playing indicated that it was not just what I did that was important, but also how I did it.

Although I felt the power of this tool in music therapy sessions, still it took much reflection and thought on my part to understand where the code fitted into my overall understanding of how I supported student participation; in the early and middle stages of data analysis, the code was present across several themes; in a later stage, as my understanding of it grew deeper, I even thought that it should be a theme in itself. Through reflection and continued review of clinical notes, I subsequently realised that I used contrasting musical elements in therapeutic facilitation for two main reasons: to reflect how the student presented, and to entice them into active participation. I then recognised that the words 'reflecting' and 
'enticing' resembled closely the theme currently being discussed, and so finally decided that it could be best understood in the context of 'following and leading'. An extract from my clinical notes of a session with $\mathrm{T}$ (August $15^{\text {th }}$ ) illustrates how I attempted to both entice and reflect a student through contrasting musical elements as I sought to be sensitive to her needs:

T moved her head, smiled gently and vocalised at different times when I sang....After I raised the energy by playing faster and louder [enticing], $T$ did not make any clear or strong response. I then brought the intensity down while singing "we'll play a little softer" [reflecting]...In a quiet space at the end of this verse, T made a soft vocalisation, which I imitated as I continued to the middle part of the song. I gradually increased the volume and frequency of my strumming [enticing], and when I sang "won't you try it out, and don't wait till later", T immediately smiled and vocalised as she looked up.

Although in this instance it is likely that the lyrical content of the song influenced T's responses, I believe that the changing nature of the music played an equal and complementary role in the supporting active student participation.

\section{CREATING A CONTACT SONG}

This involves an improvised and co-constructed piece of music between therapist and student through which the sense of mutual understanding and connection is strengthened. The meaning is unique to that particular musical relationship.

In most music therapy sessions there were uses of both pre-composed songs and improvisation. Occasionally, and with sensitive regard for a student's reaction to music, improvisations could lead to the creation of new songs in sessions. When this happened, I understood the songs to be my spontaneous and natural attempt to respond appropriately to the in the moment expressions, actions and needs of students. If a student responded positively to the new song creation, I repeated and developed it with the student to help prolong the positive interactive experience. In addition, in an attempt to replicate the perceived positive experience for the student, I often brought back the new song in future sessions. If the song elicited similar or stronger responses from students in future sessions as it did in the first instance, I retrospectively came to view the composition as our 'contact song' (see Hillman Boxill \& Chase, 2007). With contact songs, I theorised the student had such positive feelings associated with the song's moments of creation (an instinctive response of mine to an action or expression of the student), that just hearing the song again brought back positive emotions that nearly always engaged and enlivened the student. 
Some contact songs seemed to me to be stronger than others, but I felt the most prominent and enduring contact song developed during my placement was between myself and MaryJane. As shown in the vignette, I called the song 'too strong'. We sang it first in our third session together (April 3 ${ }^{\text {rd }}$ ), and it reflected my feelings after Mary-Jane had almost knocked the chimes to the ground, surprising me. That day I wrote the following in my clinical notes:

Once in a later activity, Mary-Jane almost knocked over the chimes with a sudden swing of the arm, and so I made up a song to encourage a similar vigorous effort. It seemed that she recognised what I was encouraging and that we were messing around; the frequency and strength of her chiming movements increased a lot after this.

Mary-Jane smiled, laughed and reacted animatedly whenever we began playing the song in future sessions, and I tried to keep it fresh by incorporating turn-taking aspects, introducing new lyrics, dance movements, and a series of contrasting musical renditions. I felt that this contact song and others like it (if they developed) were important in strengthening the bond between myself and students which was felt to aid the music therapy process.

\section{DYNAMIC FLOW}

In my music therapy practice I gradually developed an appreciation for all the different ways it was possible to present an activity for and with students. I developed the dynamic flow approach in the attempt to keep activities fresh and engaging for students in a way that changed the focus of attention within a given activity and provided students with ever more opportunities to explore their preferences and abilities. In short:

Dynamic flow describes an action for change timed by me to suit the perceived needs of a student, intended to keep an activity alive and interesting for both participants. It involves doing things for the student that can excite their curiosity (e.g. moving, repositioning instruments), and presenting new ways of participating that rotate the areas of focus.

Although initially the emergence of codes and my grouping of them by nature and purpose is what brought about the overall theme of dynamic flow, new and old codes continued to be removed and inserted to the long-standing dynamic flow theme throughout the analysis process. However in the final model, and as the table below illustrates, I understood that four codes could be best described within a dynamic flow framework: 


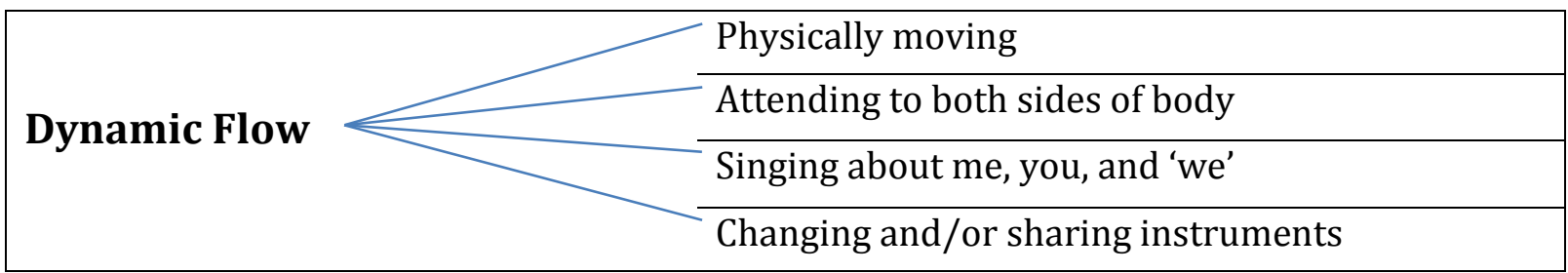

Figure 4: Theme Three Codes

\section{PHYSICALLY MOVING}

This involves taking into account how the therapist's positioning and movement in relation to students may potentially affect their participation levels.

In the earlier stages of my practice it appeared from clinical notes that I did not change position or move a lot in sessions. There is little doubt in my mind that this was in partial reflection of the young people with profound physical disabilities with whom I worked. However, I feel another reason for my relative stillness was because I had not yet acquired the experiences necessary to understand the potential value of moving and dancing for both me and students, and I became more mobile with time. With regard to students with the profoundest of physical disabilities, although I appreciated the importance of providing them with a stable environment, at the same time I recognised that moving around was something I could do to inject new energy into activities and support student engagement as the direction of sound changed ${ }^{8}$.

Furthermore, when I moved from side to side of students, their physical reactions of head turns, eye gazes or smiles in response to the changing direction of sound could give me an indication of how aware and engaged they might be. As I wrote in my clinical notes about a session with D (May 15 ${ }^{\text {th }}$ ): "He seemed to stay looking to the left for longer as I played with the guitar on that side".

One other important consideration with regard to where I placed myself in sessions appeared to be how where I stood in relation to the student's instrument affected the likelihood that they would play it. The data frequently demonstrated that whenever I stood or sat on the opposite side of a student's instrument, he or she became less active. However

\footnotetext{
${ }^{8}$ However, in reflections with colleagues it was suggested that it was important for me to take into consideration the disparity between the students' potential to move and mine, and how the student could have a different perspective of events than what I had as regards my movement. I tried to balance this aspect of my practice with remaining seated and positioned at the same eye-level of students.
} 
when I moved closer to or beside their instrument, active participation often appeared to increase.

\author{
ATTENDING TO BOTH SIDES OF BODY \\ This involves offering students opportunities to participate using both left and right \\ parts of their body as a way of developing the challenge presented to them in \\ participating. In doing so the therapist can shift focus and balance attention to both \\ sides of the body.
}

In music therapy I attempted to support students to be able to participate in a way for which they expressed a preference, and sometimes for me that meant placing instruments, such as the chimes, by their stronger side.

However, I did not want to neglect the possibility that students could gain skills and confidence in the use of their less-preferred side through participation in musical activities. As such I developed an approach whereby in sessions I would encourage students to utilise both arms and hands, although with less time spent on the side understood to be weaker. I did not emphasise the use of both sides with students who already demonstrated a functional ability with both sides, but I did want to provide an opportunity for development for those who rarely had a reason to mobilise on one side.

The clinical notes showed that I frequently gave these opportunities to students Z, MaryJane, T, and D, with varied levels of participation resulting from them. I found that a useful way to not explicitly bring attention to one side in expectation was to play the keyboard together with students, as this afforded a chance to use both hands at the same time, sometimes with my physical support.

\footnotetext{
SINGING ABOUT YOU, ME AND 'WE'

When singing lyrics, this technique is a way for the therapist to change who is being focused upon, thereby providing an opportunity for rest, listening, turn-taking or active participation for students, while also emphasising the balanced nature of the relationship.
}

In any musical interaction, there are going to be at least two participants. However in this therapeutic setting, the focus was nearly always centred on the student. Often when I sang 
adapted words to songs to suit the student, I did so using their name as I sang about what was happening and suggesting ways that they might participate. However, I began to reflect that, if our musical relationship was as equal as so often I liked to think it was, then why shouldn't I also sing about me? I thought that this change could give the student an opportunity to experience activities in another way and maybe even allow them to feel a little 'closer' to me due to my self-involvement in the actions that I was inviting them to attempt. Furthermore, I reflected that another level to the idea of what person was the subject of attention in a song, was to refer to both participants at the same time by using "we" as the key word. This notion came to me first on July $17^{\text {th }}$, when I noted the following in my reflective journal:

Is the fact that I say "we" instead of "he" very important in Z's motivation to participate? It signifies that I'll be doing it with him - we are equal. I am not requesting him to do anything that I am not going to do - we support each other.

In many sessions following this insight, I consciously used this tool (i.e. changing who was the focus of attention) to try to ensure that I was not putting undue pressure on students, and also to allow them to feel, see and hear me doing certain things. By doing so, I also considered that it was a useful method to model for students some ways they could participate in activities.

\section{CHANGING AND/OR SHARING INSTRUMENTS}

This involves periodically changing what instruments therapist and student play as a way to enhance engagement and participation.

In setting up and implementing music therapy sessions, it was first and foremost crucial to have in place instruments that students' individual abilities allowed them to access independently. The data shows that overall the chimes and the keyboard were the instruments most suited across the board to the physical capabilities of students, whereas for example instruments like the drums and xylophone were only appropriate for use with some students.

Whatever the case, I grew to learn which instruments each individual tended to actively engage with the most, and so had these present in our sessions. Quite naturally in the beginning of my practice, I would often change the instruments available to students, mostly with the start of new activities. However, with later review of data it became clear the extent to which I did this, and I began thinking about why it was so. I reflected that 
instrumental changes could serve multiple purposes. Firstly, it could give students the opportunity to explore a new instrument's sound and feeling, practise the physical skills associated with using it, and learn about their own preferences.

Additionally, I wondered if using certain instruments with particular activities in a consistent way across sessions could help some students gain a fuller understanding of session structure, what they could expect, and thus possibly give them a greater feeling of control. For example, in several sessions with A from August-November I kept the same structure of sharing guitar first, then drum and lastly xylophone before singing a goodbye song together, whilst I also tried to remain flexible enough to be able to follow A's expressions about what he wanted to do.

I could also change instruments as well as the student. Over time I developed an appreciation for finding a balance between allowing us to play instruments independently of each other, and sharing the same instrument. The clinical notes demonstrated the usefulness of this awareness on many occasions. As illustrated in the vignette, there was one part in our song 'too strong' when I would explicitly initiate a turn-taking portion of the song, singing "now Conor's gonna play the chimes (plays)...now Mary-Jane's gonna play the chimes". It was nearly always the point when she mobilised her arm independently the most.

\section{SUMMARY}

I began my practice at the school with no real experience of working with young people with PMLDs, and no fixed concepts for how I could adequately support their participation. However, with continuous reflection, review of clinical notes and regular supervision, important ideas and theories gradually emerged. The finalised themes described above illustrate what I felt was the importance of behaving in a way that promoted a collaborative partnership between myself and students, understanding who was directing activities at any time, and maintaining a dynamic flow in sessions to keep them vibrant and engaging. All three themes were felt to complement each other, with each contributing to the successful promotion of student participation when used appropriately. 


\section{DISCUSSION}

This study cannot be viewed in isolation from previous literature and research. It has been informed by the work of others, and it also relates to several aspects of past research and theories. In this section I will attempt to synthesise some of the findings from this study and find links with the literature in order to illuminate my personal insights and encourage further thinking in relevant areas.

The purpose of this study was to investigate the methods and techniques I employed as a music therapist to facilitate the participation of young people with complex needs in music therapy. It goes some way to satisfying the call of Stige (2006) that more empirical research be carried out to increase our understanding about how strategies of participation occur in various contexts. In examining and evaluating my therapeutic practice via the data sources, I gained insight into the theory and research surrounding my practice, while at the same time the research helped me to develop and enhance the quality of practice (Hillman Boxill \& Chase, 2007). Through this exploratory study, I have demonstrated that in my experience there are a high number of important factors to consider when implementing music therapy sessions for young people with complex needs. Although I was partially aware of some of these factors from the beginning of my work, I only became aware of others as a result of continuous review and reflection on my practice. Findings indicate that environmental and interpersonal elements must be carefully integrated in a thoughtful way that recognises the potential for the young people to be able to understand and learn from all interactions on a variety of levels.

\section{TIME AND CARE IN PROVISION OF A NURTURING ENVIRONMENT}

My research shows that I felt it usually took a number of months to get a strong sense of a student's personality and their preferences, and I never stopped learning about them. On many occasions, I documented the struggles I experienced in trying to form a connection with certain students, and as a result of these difficulties at the time I often wondered if I should have discontinued music therapy with the student for our mutual benefit. In such instances I was painfully aware that I had been unable to discover the strategies for forming connections with students to suit their unique characteristics, and that the barrier to their learning included my own lack of knowledge about them. The extent to which a person is considered disabled is shaped largely by the barriers to learning and functioning created by others (Adamek \& Darrow, 2010; Lebeer et al. 2012), with the World Health Organisation 
(2012) defining disability as an interaction between individuals with a health condition (e.g. cerebral palsy) and personal and environmental factors (e.g. negative attitudes and limited social supports). I felt that the need to learn about students was a strong motivator for me to experiment with different ways of interacting with them, to expand the number of opportunities for interaction (for example, through following and leading, and supporting a collaborative environment), and to ask myself how I facilitated activities with students to best suit their perceived needs and expressions. I felt that going through these processes helped my relationship with students to grow, thus assisting the progress of music therapy sessions.

\section{PROMOTING EQUAL ROLES}

In keeping with my 'person-centred' philosophy (Nordoff \& Robbins, 1977; Rogers 1995) in music therapy, during my practice I found ways to support students in taking more of an equal and leading role in the "interactional dance" (Morgan, Bruschweiler-Stern, Harrison, Lyons-Ruth, Nahum, Sander, Stern \& Tonick, 1998, p.327) of musical and interpersonal communication. Whilst difficult to always provide this support in light of my own feeling and mood on a given day, I nonetheless felt that it was highly important in my work to provide an accepting and supportive relationship to students, offering opportunities for various kinds of interactions but accepting if the student was not willing to actively participate. I believed, as Rogers (1995) claimed, that "if I can provide a certain type of relationship, the other will discover within himself the capacity to use that relationship for growth, and change and personal development will occur" (p.ix). The data from this research seemed to reinforce this belief. Patience, a cautious optimism, acceptance, and an ability to have a multi-faceted view of events were qualities and skills that I was able to document and code in my practice; I practised and developed these skills throughout my work as I sought to always maintain a positive regard for students in the face of what may have been regarded as challenging situations. Once I had sufficient knowledge about students, I endeavoured to play to their strengths, while also intermittently taking actions that I felt would perhaps challenge them in a small way to see if student growth could be supported within what I perceived to be enjoyable activities for both participants. The idea of 'small steps' is often used in relation to the development of students with PMLDs, and research conducted by Ockelford et al. (2011) assists somewhat in elucidating what this may mean when attempting to understand student growth by taking into account the levels and frequency of various kinds of musical engagement. 
For students who possessed little or no expressive language abilities - as was the case for the majority involved with this study - communication often manifested itself as a combination of vocalisations, physical movements and facial expressions, and I found that every student had ways and preferences for communicating that were unique to them. The findings provide information about a variety of musical and non-musical strategies that had the potential to acknowledge and open up the "dialogic dimension" (Gaggero, 2005, p.1039) with students. The variety was partly to do with the very particular communicating modes of students, all of which were subtle and unique.

Non-musical strategies involved engaging in musical and spoken 'conversations' with students before, during and after music therapy sessions, and continuing sensitively based on changes (or lack thereof) in student presentation and behaviour; challenging them through gesture or word at moments when I thought they would be receptive to such suggestions; and being aware of the potential impact that my own physical movement and positioning in sessions could have on student levels of engagement. The varied and imaginative use of verbal, physical, and musical behaviours (in addition to combinations of all of these) that I developed in my exploratory work builds upon the quantitative research conducted by Darrow, Johnson, Ghetti and Achey (2001) which investigated practicum behaviours of student music therapists in physical, musical and verbal domains, some having worked with populations with developmental delays and disabilities.

Although I was conscious of utilising all means and ways of interaction possible in my attempts to engage students and support their participation, I was also aware that experiences through musical interactions would be central to the development of our relationship (Miller, 2012), which I considered to be a very important factor influencing my potential to promote student development in music therapy. As a music therapy student, it was my belief and intention that experiences in music could act as "dynamic forces of change" (Bruscia, 1998, p.20) for the students with whom I worked. This positive force was evidenced time and time again when engaged in both the re-creation of pre-composed songs, and in musical improvisation. I found that for me the most powerful and meaningful interactions were those that were initiated by students. By 'initiated', I mean an independent act of communication from a student that began a musical event, or a spontaneous reaction to the existing musical environment. 


\section{LINKS WITH OTHER THEORIES OF MUSICAL PARTICIPATION}

The aspect of my findings that focused on how I developed and elaborated upon student sounds to encourage further expression and participation seems to relate closely to Ockelford's 'zygonic theory' and Holgerson's 'strategies of participation'. In 'zygonic theory', Ockelford $(2009,2012)$ purports that the chief organising force in music is imitation, and that it is primarily through imitation between participants that musical structure and development can be conceived and understood. With regard to this research, I may understand then that in my work joint improvisations with students were propelled by the acknowledgement of each other's attempts at imitating aspects of the other's playing through musical qualities such as pitch, melody, duration, and the like. However, although imitation seemed to have been a powerful tool for supporting interactive participation, in my development of student sounds and musical contributions I found that sustained improvisational interaction could be achieved by finding a balance between using and diverging from the musical ideas of students. This sometimes resulted in the student having an implicit 'part' to play at regular intervals, while I developed their idea in a way that stemmed from their input, but also diverged significantly from it before inviting the student back in once more. My feeling that often students understood the implicit nature of our roles in such interactions seems to correspond with Holgersen's musical participation strategy of 'identification': a person's demonstration that they are aware of and understand the general idea of an ongoing activity (2010). In terms of zygonic theory, the divergence of my playing from the contribution of students (i.e. not exactly imitating) could be seen to be somewhat equivalent to Ockelford's concept of 'autonomy', with the opposite idea of 'control' being when one participant copies the other's music exactly (2012). Young (2005) also talks about the importance of musical imitation and elaboration in a positive musical interaction. While conscious of the necessarily inter-dependent nature of my relationship with students in music therapy sessions, still I remained aware of the goal to support their need to act and communicate independently.

\section{IS 'ACTIVE PARTICIPATION' THE ONLY WAY TO PARTICIPATE?}

In much of my music therapy work I made strong efforts to engage students in active participation through a variety of means, and this reflects a prevalent view that eliciting active participation in communicative music-making can achieve beneficial results (Ansdell \& Pavlicevic, 2005). Some of the techniques and methods used to achieve educational and developmental goals for students included improvisation, singing, dancing, lyric adaptation 
to pre-composed songs, instrumental playing, and music listening (Daveson \& Edwards, 1998). However, with constant gestural and explicit invitations to participate comes the danger of over-prompting students to act and respond in certain ways, which can actually obstruct learning by not allowing students to think for themselves (Gallego, 2006). It took time and experience to teach me that encouraging active participation may not have always been the best way forward for students, depending on their mood or the environment. I learned that I could sing about me (and 'we') instead of only them, and that at times it was beneficial for me to play without necessarily expecting anything or hoping that students would participate in a particular way, although of course I would reflect upon such instances in detail after sessions. I found it useful to vary the level of participation that I expected of students based on their abilities, how they presented in music therapy sessions, and sometimes based on the feedback teachers gave me about how students were 'feeling' on a particular day (see Adamek \& Darrow, 2010). As Standley and Jones (2007) state, students can also participate by observing, listening, and being aware of other people's actions, and learn vicariously through observation of role models. Holgersen (2010) seems to be in agreement, saying that this type of behaviour can be a legitimate form of participation, using the term 'reception' to describe when a young person is engaged in a shared activity by listening and watching.

In conversations with staff member D I became aware of the idea that different students respond uniquely to various sensory stimulation, be it aural, tactile, visual, or otherwise. The notion of all students having different sensory thresholds appealed to me, as it made me think more about how I utilised textural, harmonic, rhythmic and melodic elements of music to best suit the sensory needs of students so that they could at least be open and receptive to my presence and actions. Along these lines, Schwartz (2008) noted that music has the ability to "bring people into an optimal level of arousal that is conducive to learning through the sensory stimulation it provides" (p.8). It thus seems that knowing whether some students may learn better if sensory input is higher or lower may be very important for the planning and implementation of sessions with students sensitive in these ways.

\section{FINAL THOUGHTS}

Care needs to be taken to always support students' feeling that they are in control of their environment through a process of informing, listening, asking questions, and responding appropriately to their physical and vocal expressions. The findings indicate also that there 
is a need for staff to be creative and imaginative when thinking of ways to increase students' reasons for communicating and participating in activities and to recognise that there may be many latent opportunities for interaction present at any given moment in the right environment. Indeed, special needs expert Lavoie (cited in Darrow, 2012) believes that having students with learning difficulties makes teachers and therapists more creative in an effort to find ways to successfully promote student learning. It is crucial that people working with students with PMLDs keep high expectations of what students are capable of and continue to challenge them and initiate meaningful and genuine interactions. Through a process of repetition and familiarisation with tasks, students may become more likely to participate in functional and musical activities. Although students may not exhibit a certain skill or knowledge at one time, this does not mean that they have not got the potential to learn given the right support and environment conducive to growth, relationship-building and positive development. Like anyone else, young people with PMLDs deserve a diverse range of reasons to communicate, and through music therapy and other activities they can increase the means through which they do so. At the same time professionals, family, and friends can increase their ability to interpret and understand such communications, and contribute towards the holistic development and wellbeing of young people with PMLDs.

\section{LIMITATIONS OF RESEARCH}

This study was based upon my direct experiences with students with PMLDs in the school, and I acted in the role of both practitioner and researcher. All data sources were created by me, and although others may have contributed their thoughts and opinions about various aspects of my work, in the end I personally documented communications if I interpreted that they could be meaningful for the future progress of the research. Due to personal and practical issues, it was not always possible to record every potentially meaningful discussion. In addition, it is important to be aware that my interpretations of student behaviour and feeling in this study were only tentative attempts at doing so, however informed by past experiences and increasing knowledge of students. I had no way to confirm or deny any thoughts or suspicions with regard to student perspective, and as such cannot claim any absolute truth in my descriptions of this type.

The data gathered had been done so to keep an adequate record of events surrounding my music therapy practice. However as the areas of research became more focused as the year progressed I must acknowledge that the themes and codes that emerged could have 
partially influenced my behaviours in music therapy, my interpretations of events and how I wrote my clinical notes. I was aware of the potential for this to happen, but with continuous supervision I was assisted in keeping an open mind so as to prevent preconceived ideas blocking the potential for gaining new and valuable insights. At the same time, I wished to use my past experiences and learning to inform how I behaved in subsequent music therapy sessions in order to improve my practice and abilities to facilitate student participation.

This research was specific to my music therapy work in one school, and thus generalisations cannot be drawn from my findings. Claims should be interpreted with diligence and caution, and hopefully be utilised to inform but not direct future work in this area. 


\section{CONCLUSIONS}

Young people with complex needs have a capacity to participate in music therapy in a number of meaningful ways. With the sensitive support of educators and therapists, they can be active agents in their own learning and development. This explorative study, intended to investigate my practice as a music therapist working with young people with PMLDs, revealed that the strategies and techniques I developed to support the participation of students fell into three main thematic categories: creating a collaborative environment, following and leading, and maintaining a dynamic flow in musical activities. Whilst the codes within these themes may not be conceptually discrete and may be understood to overlap across themes somewhat, they have been helpful in articulating and sharing the meaning and categories of music and non-musical behaviour I engaged in while in music therapy sessions with students.

The data for this research was gathered throughout a nine-month placement period I spent working as a music therapy student in the school, and this amount of time allowed me to learn about the young people with PMLDs in a natural way, and helped me to progressively improve my practice as it applied to the unique needs of every young person. Given the right environment, choice, and multiple ways to have their presence valued in non-musical as well as musical ways, students engaged in a wide array of activities that ranged from following spoken suggestions, to learning new musical frameworks in which they could express themselves, be heard, and develop skills. The relationships built over the course of many music therapy sessions between students and I were important for the uncovering of existing and emergent skills, as well as in discovering new activities that could engage students in enjoyable ways. Students can respond positively to carefully-timed challenges that suggest and encourage different modes of participation, but it is also important, in my experience, for practitioners to recognise and respond sensitively when it seems that students are challenging them. At the very least, educators and therapists can inform students about their environment and options through the use of visual, tactile and aural cues, giving them the opportunity to think and make decisions for themselves in a way that gives them control over activities and the part they choose to play in them.

\section{RECOMMENDATIONS FOR FUTURE RESEARCH}

Whilst this research looked into the methods and techniques I utilised to help promote the participation of individual students with PMLDs in music therapy, further exploration may 
be necessary to enhance understanding about student actions, reactions, thoughts and feelings in music therapy. However this may be challenging given the profound communication difficulties exhibited by the population involved in this research, and such a study may well require an interpretive approach from researchers. In addition, future studies could investigate staff and student behaviours in group music therapy sessions in order to explore how behaviours in these sessions may differ from one-to-one interactions. Lastly, my experiences in this research indicate that it could be valuable to video-record music therapy sessions, as this may help in subsequent reflections with colleagues who may not have been present at the time of therapy. In addition to practitioners documenting richly their own feelings, thoughts and insights on sessions from memory, a recording can provide a viewpoint from which other observers can share and compare perceptions in later reviews. This may allow for a wider perspective than the lens I have been able to provide in the current study. 


\section{REFERENCES}

Adamek, M. (2002). In the Beginning: A Review of Early Special Education Services and Legislative/Regulatory Activity Affecting the Teaching and Placement of Special Learners. In B. Wilson (Ed.), Models of Music Therapy Interventions in School Settings (pp. 15-24). Silver Spring, USA: American Music Therapy Association.

Adamek, M. \& Darrow, A. (2010). Music in Special Education. Silver Spring, MD: American Music Therapy Association.

Aigen, K. (2005). Playin' in a Band: A Qualitative Study of Popular Music Styles as Clinical Improvisation. Gilsum, NH: Barcelona Publishers.

Aldridge, D. (1996). Music Therapy Research and Practice in Medicine: From Out of the Silence. London: Jessica Kingsley.

Aldridge, D., Gustorff, D. \& Neugebauer, L. (1995). A Preliminary Study of Creative Music Therapy in the Treatment of Children with Developmental Delay. The Arts in Psychotherapy, 22(3), 189-205. Retrieved from

http://www.sciencedirect.com.ezproxy.massey.ac.nz/science/article/pii/01974556950001 92

Ansdell, G. \& Pavlicevic, M. (2005). Music Companionship, Musical Community: Music Therapy and the Process and Value of Musical Communication. In D. Miell, R. MacDonald \& D. Hargreaves (Eds.), Musical Communication (pp. 193-214). Oxford: Oxford University Press.

Auslander, G. \& Gold, N. (1999). Disability Terminology in the Media: A Comparison of Newspaper Reports in Canada and Israel. Social Science and Medicine, 48(10), 1395-1405. Retrieved from http://www.sciencedirect.com.ezproxy.massey.ac.nz/science/article/pii/S0277953698004 420

Bellamy, G., Croot, L., Bush, A., Berry, H., \& Smith, A. (2010). A Study to Define: Profound and Multiple Learning Disabilities (PMLD). Journal of Intellectual Disabilities, 14(3), 221-235. Retrieved from http://jid.sagepub.com.ezproxy.massey.ac.nz/content/14/3/221.short

Braun, V. \& Clarke, V. (2006). Using Thematic Analysis in Psychology. Qualitative Research in Psychology, 3(2), 77-101. Retrieved from http://www.tandfonline.com.ezproxy.massey.ac.nz/doi/abs/10.1191/1478088706qp063o a

Brown, L. \& Jellison, J. (2012). Music Research with Children and Youth with Disabilities and Typically Developing Peers: A Systematic Review. Journal of Music Therapy, 49(3), 335-364.

Bruscia, K. (1987). Improvisational Models of Music Therapy. Springfield, IL: Charles C. Thomas.

Bruscia, K. (1995). The Process of Doing Qualitative Research. In B. Wheeler (Ed.), Music Therapy Research: Quantitative and Qualitative Perspectives (pp. 389-400). Gilsum, NH: Barcelona Publishers. 
Bruscia, K. (1998). Defining Music Therapy. Gilsum: Barcelona Publishers.

Bruscia, K. (2005). Standards of Integrity for Qualitative Music Therapy Research. Voices: A World Forum for Music Therapy, 5(3). Retrieved from https://normt.uib.no/index.php/voices/article/viewArticle/238/182

Brunk, B. \& Coleman, K. (2002). A Special Education Music Therapy Assessment Process. In B. Wilson (Ed.), Models of Music Therapy Interventions in School Settings (pp. 69-82). Silver Spring, USA: American Music Therapy Association.

Cannella, H., O’Reilly, M. \& Lancioni, G. (2005). Choice and Preference Assessment Research with People with Severe to Profound Developmental Disabilities: A Review of the Literature. Research in Developmental Disabilities, 26(1), 1-15. Retrieved from http://www.sciencedirect.com.ezproxy.massey.ac.nz/science/article/pii/S0891422204000 733

Carson, D., Gilmore, A., Perry, C. \& Gronhaug K. (2001). Qualitative Marketing Research. London: Sage Publications Inc..

Cerebral Palsy Society of New Zealand (2007). Cerebral Palsy. Retrieved from http://www.cpsoc.org.nz/

Coleman, K. (2002). Music Therapy for Learners with Severe Disabilities in a Public School Setting. In B. Wilson (Ed.), Models of Music Therapy Interventions in School Settings (pp. 197210). Silver Spring, USA: American Music Therapy Association.

Darrow, A., Johnson, C., Ghetti, C. \& Achey, C. (2001). An Analysis of Music Therapy Student Practicum Behaviors and their Relationship to Clinical Effectiveness: An Exploratory Investigation. Journal of Music Therapy, 38(4), 307-320.

Darrow, A., Colwell, C. \& Kim, J. (2002). Research on Mainstreaming: Implications for Music Therapists. In B. Wilson (Ed.), Models of Music Therapy Interventions in School Settings (pp. 41-67). Silver Spring, USA: American Music Therapy Association.

Darrow, A. (2012). Students with Learning Disabilities in the Music Classroom. General Music Today, 26(1), 41-43. Retrieved from http://gmt.sagepub.com.ezproxy.massey.ac.nz/content/26/1/41.short

Daveson, B. \& Edwards, J. (1998). A Role for Music Therapy in Special Education. International Journal of Disability, Development and Education, 45(4), 449-457. Retrieved from http://www.tandfonline.com.ezproxy.massey.ac.nz/doi/abs/10.1080/1034912980450407

Elliot, D. \& Silverman, M. (2012). Why Music Matters: Philosophical and Cultural Foundations. In R. MacDonald, G. Kreutz \& L. Mitchell (Eds.), Music, Health and Wellbeing (pp. 25-39). Oxford: Oxford University Press.

Gaggero, G. (2005). “Meaning” in Music Therapy. Music Therapy Today, 6(4), 1022-1043. Retrieved from http://www.wfmt.info/Musictherapyworld/modules/mmmagazine/index.html 
Gallegos, J. (2006). Judith A. Jellison: Music and Children with Special Needs. Intervention in School and Clinic, 42(1), 46-50. Retrieved from

http://isc.sagepub.com.ezproxy.massey.ac.nz/content/42/1/46.short

Gembris, H. (2012). Music-Making as a Lifelong Development and Resource for Health. In R. MacDonald, G. Kreutz \& L. Mitchell (Eds.), Music, Health and Wellbeing (pp. 367-382).

Oxford: Oxford University Press.

Gibbs, G. (2007). Analyzing Qualitative Data. London: Sage Publications Inc.

Gibson, W. \& Brown, A. (2009). Working with Qualitative Data. Los Angeles: Sage

Publication Inc.

Green, C. \& Reid, D. (1996). Defining, Validating, and Increasing Indices of Happiness Among People with Profound Multiple Disabilities. Journal of Applied Behavior Analysis, 29(1), 67-

78. Retrieved from http://www-ncbi-nlm-nih-

gov.ezproxy.massey.ac.nz/pmc/articles/PMC1279874/

Grove, N., Bunning, K., Porter, J. \& Olsson, C. (1999). See What I Mean: Interpreting the Meaning of Communication by People with Severe and Profound Intellectual Disabilities. Journal of Applied Research in Intellectual Disabilities, 12(3), 190-203. Retrieved from http://onlinelibrary.wiley.com.ezproxy.massey.ac.nz/doi/10.1111/j.1468-

3148.1999.tb00076.x/abstract

Hanser, S. (1987). Music Therapist's Handbook. St. Louis, MO: Warren H. Green, Inc.

Heaton, J. (2008). Secondary Analysis of Qualitative Data. In P. Alasuutari, L. Bickman \& J. Brannen (Eds.), The SAGE Handbook of Social Research Methods (pp. 506-519). London: Sage Publications Inc.

Hillman Boxill, E. \& Chase, K. (2007). Music Therapy for Developmental Disabilities. Austin, TX: Pro-Ed.

Holgersen, S. (2010). Body Consciousness and Somaesthetics in Music Education. Action, Criticism, and Theory for Music Education, 9(1), 31-44. Retrieved from http://act.maydaygroup.org/articles/Holgersen9_1.pdf

Jellison, J. (2000). A Content Analysis of Music Research with Disabled Children and Youth (1975-1999): Applications in Special Education. In C. Furman (Ed.), Effectiveness of Music Therapy Procedures: Documentation of Research and Clinical Practice (pp. 199-264). Silver Spring, MD: American Music Therapy Association.

Johnson, F. (2002). Models of Service Delivery and Their Relation to the IEP. In B. Wilson (Ed.), Models of Music Therapy Interventions in School Settings (pp. 83-107). Silver Spring, USA: American Music Therapy Association.

Kenny, C., Jahn-Langenberg, M. \& Loewy, J. (2005). Hermeneutic Inquiry. In B. Wheeler (Ed.), Music Therapy Research (pp. 335-350). Gilsum, NH: Barcelona Publishers.

Kimi Ora School (2012). Staff Handbook. Wellington, New Zealand: Author.

Lave, J. \& Wenger, E. (1991). Situated Learning: Legitimate Peripheral Participation. Cambridge: Cambridge University Press. 
Lebeer, J., Birta-Székely, N., Demeter, K., Bohács, K., Candeias, A., Sønnesyn, G., Partanen, P. \& Dawson, L. (2012). Re-assessing the Current Assessment Practice of Children with Special Education Needs in Europe. School Psychology International, 33(1), 69-92. Retrieved from http://spi.sagepub.com.ezproxy.massey.ac.nz/content/33/1/69.short

Lee, J. \& McFerran, K. (2012). The Improvement of Non-Verbal Communication Skills of Five Females with Profound and Multiple Disabilities Using Song-Choices in Music Therapy. Voices: A World Forum for Music Therapy, 12(3). Retrieved from https://normt.uib.no/index.php/voices/article/view/644/559

Littell, J., Alexander, L. \& Reynolds, W. (2001). Client Participation: Central and Underinvestigated Elements of Intervention. Social Service Review, 75(1), 1-28. Retrieved from http://www.jstor.org.ezproxy.massey.ac.nz/stable/10.1086/591880

Malloch, S. \& Trevarthen, C. (2009). Musicality: Communicating the Vitality and Interests of Life. In S. Malloch \& C. Trevarthen (Eds.), Communicative Musicality: Exploring the Basis of Human Companionship. Oxford: Oxford University Press.

Marshall, C. \& Rossman, G. (2010). Designing Qualitative Research. London: Sage Publications Inc.

McFerran, K. (2012). Who is My "Client"? Voices: A World Forum for Music Therapy. Retrieved from http://testvoices.uib.no/?q=fortnightly-columns/2012-who-my-client

Merleau Ponty, M. (2011). Phenomenology of Perception. New York: Routledge.

Miller, E. (2012). Music Therapy Students' Experiences of Interactions with Young Clients During Fieldwork Placement. Voices: A World Forum for Music Therapy, 12(2). Retrieved from https://normt.uib.no/index.php/voices/article/view/626

Ministry of Education (2007). Key Competencies: Capabilities for Living and Lifelong Learning. Retrieved from http://nzcurriculum.tki.org.nz/Curriculum-documents/The-NewZealand-Curriculum/Key-competencies

Ministry of Education (2012). Individual Education Plans (IEP). Retrieved from http://www.minedu.govt.nz/NZEducation/EducationPolicies/SpecialEducation/ServicesA ndSupport/IndividualEducationPlans.aspx

Ministry of Education (2012). Ongoing Resourcing Scheme. Retrieved from http://www.minedu.govt.nz/NZEducation/EducationPolicies/SpecialEducation/ServicesA ndSupport/OngoingResourcingScheme.aspx

Morgan, A., Bruschweiler-Stern, N., Harrison, A., Lyons-Ruth, K., Nahum, J., Sander, L., Stern, D. \& Tronick, E. (1998). Moving Along to Things Left Undone. Infant Mental Health Journal, 19(3), 324-332. Retrieved from http://onlinelibrary.wiley.com/doi/10.1002/\%28SICI\%2910970355\%28199823\%2919:3\%3C324::AID-IMHJ9\%3E3.0.CO;2-L/abstract

Nordoff, P. \& Robbins, C. (1977). Creative Music Therapy: Individualized Treatment for the Handicapped Child. New York: John Day.

Nordoff, P. \& Robbins, C. (1983). Music Therapy in Special Education. St. Louis, MO: Magnamusic-Baton. 
NZSM, M.T.D. (2011). Ethical Guidelines for NZSM526 Research Projects. Wellington: New Zealand School of Music.

O’Brien, P. \& Ryba, K. (2005). Policies and Systems in Special Education. In D. Fraser, R. Moltzen \& K. Ryba (Eds.), Learners with Special Needs in Aotearoa New Zealand (pp. 22-48). Palmerston North, New Zealand: Dunmore Press.

Ockelford, A. (2000). Music in the Education of Children with Severe or Profound Learning Difficulties: Issues in Current U.K. Provision, A New Conceptual Framework, and Proposals for Research, Psychology of Music, 28(2), 197-217. Retrieved from http://pom.sagepub.com.ezproxy.massey.ac.nz/content/28/2/197.short

Ockelford, A. (2008). Music for Children and Young People with Complex Needs. Oxford: Oxford University Press.

Ockelford, A. (2009). Zygonic Theory: Introduction, Scope, and Prospects. Zeitschrift der Gesellschaft für Musiktheorie, 6(1), 91-172. Retrieved from http://www.gmth.de/zeitschrift/artikel/400.aspx

Ockelford, A. (2012). Songs Without Words: Exploring How Music Can Serve as a Proxy Language in Social Interaction with Autistic Children. In R. MacDonald, G. Kreutz \& L. Mitchell (Eds.), Music, Health and Wellbeing (pp. 289-323). Oxford: Oxford University Press.

Ockelford, A. \& Markou, K. (2012). Music Education and Therapy for Children and Young People with Cognitive Impairments: Reporting on a Decade of Research. In R. MacDonald, G. Kreutz \& L. Mitchell (Eds.), Music, Health and Wellbeing (pp. 383-402). Oxford: Oxford University Press.

Ockelford, A., Welch, G., Jewell-Gore, L., Cheng, E., Vogiatzoglou, A. \& Himonides, E. (2011). Sounds of Intent, Phase 2: Gauging the Music Development of Children with Complex Needs. European Journal of Special Needs Education, 26(2), 177-199. Retrieved from http://www.tandfonline.com.ezproxy.massey.ac.nz/doi/abs/10.1080/08856257.2011.563 606

Patterson, A. (2003). Music Teachers and Music Therapists: Helping Children Together. Music Educators Journal, 89(4), 35-39. Retrieved from http://web.ebscohost.com.ezproxy.massey.ac.nz/ehost/detail?sid=b15abe84-4115-4228$83 \mathrm{cc}-$ d769db5a7063\%40sessionmgr4\&vid=1\&hid=24\&bdata=JkF1dGhUeXBlPWlwLGNvb2tpZSx 1cmwsdWlkJnNpdGU9ZWhvc3QtbGl2ZQ\%3d\%3d\#db=ehh\&jid=MUE

Patton, M. (2002). Qualitative Research and Evaluation Methods. Thousand Oaks, CA: Sage Publications Inc.

Perry, M. (2011). Having Another Look at Cerebral Palsy: Current Definitions and Classification Systems. Voices: A World Forum for Music Therapy, 11(1). Retrieved from https://normt.uib.no/index.php/voices/article/viewArticle/290/443

PMLD Network (2012). People with Profound and Multiple Learning Difficulties. Retrieved from http://www.pmldnetwork.org/what_do_we_want/who_are_we_campaigning_for.htm 
Porter, J., Ouvry, C., Morgan M. \& Downs, C. (2001). Interpreting the Communication of Young People with Profound and Multiple Learning Difficulties. British Journal of Learning Disabilities, 29(1), 12-16. Retrieved from

http://web.ebscohost.com.ezproxy.massey.ac.nz/ehost/detail?sid=028fafee-a26a-4b29b5ad-

9f49da2b0d93\%40sessionmgr114\&vid=1\&hid=111\&bdata=JkF1dGhUeXBlPWlwLGNvb2tp ZSx1cmwsdWlkJnNpdGU9ZWhvc3QtbGl2ZQ\%3d\%3d\#db=ehh\&jid=F04

Richards, L. (2009). Handling Qualitative Data: A Practical Guide. London: Sage Publications Inc.

Rickson, D. (2010). The Development of a Music Therapy School Consultation Protocol for Students with High or Very High Special Education Needs (Doctoral thesis, NZSM, Massey and Victoria Universities, Wellington, New Zealand). Retrieved from http://mro.massey.ac.nz/handle/10179/1881

Rogers, C. (1995). On Becoming a Person: A Therapist's View of Psychotherapy. Boston: Houghton Mifflin.

Rosenbaum, P., Paneth, N., Leviton, A., Murray, G. \& Bax, M. (2006). A Report: The Definition and Classification of Cerebral Palsy. Developmental Medicine and Child Neurology, 49(1), 814. Retrieved from http://onlinelibrary.wiley.com/doi/10.1111/j.14698749.2007.tb12610.x/pdf

Schwandt, T. (2007). The Sage Dictionary of Qualitative Inquiry. Los Angeles: Sage Publications Inc.

Schwartz, E. (2008). Music, Therapy, and Early Childhood: A Developmental Approach. Gilsum, NH: Barcelona Publishers.

Shoemark, H. (2007). The Markers of Interplay Between the Music Therapist and the Medically Fragile Newborn Infant (Doctoral dissertation, University of Melbourne, Victoria, Australia). Retrieved from http://dtl.unimelb.edu.au/R/FXGJFHR3RHP1B4LNAE5MI3CFSLQ62QFVC7CTTN844AAPYK I8S1-00946?func=dbin-jumpfull\&object_id=67707\&local_base=GEN01\&pds_handle=GUEST

Simeonsson, R., Carlson, D., Huntington, G., McMillen, J. \& Brent, J. (2001). Students with Disabilities: A National Survey of Participation in School Activities. Disability and Rehabilitation, 23(2), 49-63. Retrieved from http://informahealthcare.com.ezproxy.massey.ac.nz/doi/pdf/10.1080/096382801750058 134

Simmons, B. (2011). The "PMLD Ambiguity": Articulating the Lifeworlds of Children with Profound and Multiple Learning Difficulties. Paper presented at the Nordic Network on Disability Research 11th Annual Conference, Reykjavík, Iceland.

Smith, A., Bihm, E., Tavkar, P. \& Sturmey, P. (2005). Approach-Avoidance and Happiness Indicators in Natural Environments: A Preliminary Analysis of the Stimulus Preference Coding System. Research in Developmental Disabilities, 26(3), 297-313. Retrieved from http://www.sciencedirect.com.ezproxy.massey.ac.nz/science/article/pii/S0891422204001 167 
Standley, J. \& Jones, D. (2007). Music Techniques in Therapy, Counselling, and Special Education. Silver Springs, MD: American Music Therapy Association.

Stige, B. (2006). On a Notion of Participation in Music Therapy. Nordic Journal of Music Therapy, 15(2), 121-138. Retrieved from http://www.tandfonline.com.ezproxy.massey.ac.nz/doi/abs/10.1080/0809813060947815 9

Stige, B. \& Aarø, L.E. (2012). Invitation to Community Music Therapy. New York: Routledge. Taylor, C. (2008). "Both Sides, Now": Balancing the Extrinsic and Intrinsic Benefits of Music in Music Advocacy. The Canadian Music Educator, 49(3), 36-38. Retrieved from http://web.ebscohost.com.ezproxy.massey.ac.nz/ehost/detail?sid=8599434b-0021-400baefb-

2b630ca6b906\%40sessionmgr111\&vid=1\&hid=111\&bdata=JkF1dGhUeXBlPWlwLGNvb2tp ZSx1cmwsdWlkJnNpdGU9ZWhvc3QtbGl2ZQ\%3d\%3d\#db=ehh\&jid=177C

Taylor, K. (2008). The Participation of Children with Multi-Sensory Impairment in PersonCentred Planning. British Journal of Special Education, 34(4), 204-211. Retrieved from http://onlinelibrary.wiley.com/doi/10.1111/j.1467-8578.2007.00480.x/abstract

Thorne, S. (1998). Ethical and Representational Issues in Qualitative Secondary Analysis. Qualitative Health Research, 8(4), 547-555. Retrieved from http://qhr.sagepub.com.ezproxy.massey.ac.nz/content/8/4/547.short

Trevarthen, C. \& Malloch, S. (2000). The Dance of Wellbeing: Defining the Musical Therapeutic Effect. Nordic Journal of Music Therapy, 9(2), 3-17. Retrieved from http://www.tandfonline.com.ezproxy.massey.ac.nz/doi/abs/10.1080/0809813000947799 6

United Nations (2006). Convention on the Rights of Persons with Disabilities. Retrieved from http://www.un.org/disabilities/default.asp?id=199

Ware, J. (2003). Creating a Responsive Environment for People with Profound and Multiple Learning Difficulties. London: David Fulton Publishers.

Ware, J. (2004). Ascertaining the Views of People with Profound and Multiple Learning Disabilities. British Journal of Learning Disabilities, 32(4), 175-179. Retrieved from http://onlinelibrary.wiley.com.ezproxy.massey.ac.nz/doi/10.1111/j.14683156.2004.00316.x/full

Welch, G., Ockelford, A., Carter, F., Zimmermann, S. \& Himonides, E. (2009). 'Sounds of Intent': Mapping Musical Behaviour and Development in Children and Young People with Complex Needs. Psychology of Music, 37(3), 348-370. Retrieved from http://pom.sagepub.com.ezproxy.massey.ac.nz/content/37/3/348.short

Wheeler, B., Shultis, C. \& Polen, D. (2005). Clinical Training Guide for the Student Music Therapist. Gilsum, NH: Barcelona Publishers.

World Health Organisation (2012). Disability and Health. Retrieved from http://www.who.int/mediacentre/factsheets/fs352/en/ 
World Health Organisation \& World Bank (2001). World Report on Disability Summary: EasyRead Version. Retrieved from

http://www.who.int/disabilities/world_report/2011/report/en/

Wigram, T. (2004). Improvisation: Methods and Techniques for Music Therapy Clinicians, Educators and Students. London: Jessica Kingsley Publishers.

Young, S. (2005). Musical Communication Between Adults and Young Children. In D. Miell, R. MacDonald \& D. Hargreaves (Eds.), Musical Communication (pp. 281-299). Oxford: Oxford University Press. 


\section{APPENDIX 1: GLOSSARY OF TERMS}

Cerebral Palsy: An umbrella term encompassing a group of non-progressive motor conditions. It is a disorder of movement, muscle tone or posture that is caused by damage to the motor control centres of the developing brain. It is often accompanied by disturbances of sensation, cognition, communication, perception, behaviour, and/or epilepsy (Cerebral Palsy Society of New Zealand, 2007).

Cortical Visual Impairment: Visual impairment caused by damage to the visual cortex of the brain, or pathways between the eye and brain, that results in the brain not accurately interpreting visual information received through the eye. The eye itself is structurally healthy, but because the brain has difficulty processing visual information, sight is restricted (Adamek \& Darrow, 2010).

Disability: An interaction between individuals with a health condition, and personal and environmental factors (World Health Organisation, 2012).

Individual Education Plan (IEP): Sets educational and developmental goals for the young person and identifies how they will be supported to meet those goals. It is developed by the team of people who support a child and young person, including their parents, family, whānau and the young person themselves. It identifies teaching and learning strategies that will support the young person's needs, and ways to check for progress (Ministry of Education, 2012).

Key Competencies: Areas considered to be important for student growth and wellbeing, considered to underpin their ability to learn in every domain. There are currently five key competencies: 1) managing self, 2) participating and contributing, 3) relating to others, 4) thinking, and 5) using language symbols and texts (Ministry of Education, 2007).

Profound and Multiple Learning Difficulties (PMLDs): People with PMLDs -

- have more than one disability

- have a profound learning disability

- have great difficulty communicating

- need high levels of support

- may have additional sensory or physical disabilities, complex health needs or mental health difficulties

- may have behaviours that challenge us (PMLD Network, 2012)

Switch: A device to communicate a simple message, often to answer a question with yes or no, to participate in a shared story, and for other communicative purposes. 
Conor Clerkin,

Master of Music Therapy Student

New Zealand School of Music,

Mt. Cook,

Wellington 6140,

PO Box 2332

November 01, 2012

Dear family,

I am a student music therapist, working with $\quad$ School since March of this year. I have been involved with in music therapy since quite early on in my work placement at and indeed I am lucky to have had the pleasure to meet you all at

I am writing today to inform you about my upcoming research and to ask if you would find it acceptable that I review and include information involving my experiences with 1 in music therapy in my research. I have valued highly the time that I have been able to spend with over the past few months, getting to know her as a student, and more generally as a person.

I have attached an information sheet to this letter so that you can acquaint yourselves with my work and study, and feel comfortable about what I am asking of you. Following a reading of the information sheet, if you are satisfied that everything is in order the next step would be to consider signing the consent form (also attached). This would give permission for me to utilise notes I have generated while working with or the purposes of building my research project.

I would be grateful if you could respond or return the information and consent forms by Tuesday, November $6^{\text {th }}$, however there is some leeway if you wish to consider my request in more detail, as this is your prerogative. I would be happy to collect the forms from in school next week, if you think that would be the best method for returning them to me.

I look forward to hearing from you,

Conor Clerkin 


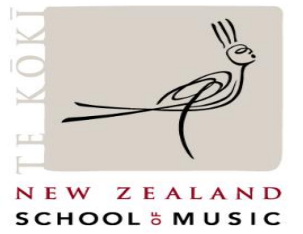

\title{
Information Sheet for Parents/Guardians - Review of Records in a Music Therapy Research Project
}

\author{
Title of Project: How are Students with Complex Needs Supported to Participate in Music Therapy: \\ Understanding and Evaluating Interactions
}

Dear family,

My name is Conor Clerkin, and I am a Master of Music Therapy student with the New Zealand School of Music. As part of my second year assessment, I have been working at 1 School on a year-long clinical work placement to practice my skills as a music therapist. As well as enhancing the education and wellbeing of the students at my work at the school is also aimed at helping me progress as a clinician and researcher. I am writing to you because I would like to review documentation that was generated as part of my clinical practice, and which relates to you, within my research project. I will now tell you about the research.

\section{The Research}

In my work at I quickly became interested in the qualities of interactions between myself and students in music therapy. In particular, I wished to uncover what techniques and methods I used to facilitate learning experiences for the students. I have been keeping clinical and reflective notes throughout my work to document my practice and experiences, and reviewing them by way of a 'secondary analysis'. This means that for the most part music therapy was carried out as if no research was occurring. Once I had formulated a research question based on experiences in music therapy, I began reviewing the clinical documentation with that particular focus in mind, while still continuing music therapy as it always would have been for the sake of the students' learning and wellbeing.

\section{Why Records are being Requested for Review}

Currently I have permission from Massey University, the New Zealand School of Music, and 1 to carry out my work as a music therapist and researcher. I have been recording my observations and thoughts as part of my work as a music therapist with a view to improving my music therapy services for the students. However, in order to use these written documents to answer my research question, I need to gain informed consent from the school, students, their families, and any other significant parties involved. Should you give permission for me to review records in research, I will be including a short story-like description of a music therapy session in which $\quad$ has participated to help me illustrate central points of my thesis. This vignette, as it is officially known, will describe in some detail, and whilst I will de-identify names and places as much as possible for sake of facility and personal anonymity, there will still be a chance that readers of the research may be able to figure out the location of work and people involved. I will need your informed consent to allow me to review and include information from my clinical and reflective notes involving in my research project. Should you be happy to provide consent, this could enable me to better answer my research question and potentially help future music therapists enhance their clinical skills for the benefit of young people with special needs. 


\section{Sources to be Used}

In the course of my work placement at I have been keeping clinical notes, a personal reflective journal, and sometimes using audiovisual recordings to enhance the accuracy and richness of my thoughts about music therapy sessions. In addition, when possible I have also been documenting personal communications with staff, students and parents in settings outside of music therapy, as well as notating music played in sessions.

\section{How Sources will be Used and Stored}

As a student acting under the ethical guidelines of Massey University and Music Therapy New Zealand, it is my responsibility to ensure that all the information I collect is treated in a way that maintains the integrity of those whom it concerns. As such, I have been and will be taking measures to safeguard records containing potentially sensitive information. The clinical notes I have written from my time at are being stored on the password protected computers in the school, meaning that only you or I can access them from there. I also keep a copy of my notes on my personal computer at home, and on a private memory disk. Any audiovisual material of students or staff in music therapy sessions that I have recorded has been quickly transferred from recording devices onto the school online server. Original recordings are then deleted from the camera. All handwritten material is kept securely in my private room at home. I am careful to disguise or omit any sensitive information in documents in order to deidentify those who are involved, and to protect the integrity of those associated with them. However, due to the nature of the small music therapy community in New Zealand as well as the type of school facility in question, it is possible that people and places may be identifiable by readers of the research.

This project has been reviewed and approved by the New Zealand School of Music Postgraduate committee. The Chairs of Massey University Human Ethics and Health and Disability Ethics Committees have given generic approval for music therapy students to conduct studies of this type, which have been judged to be low risk and, consequently, are not separately reviewed by any Human Ethics Committees. The supervisor named at the end of this information sheet is responsible for the ethical conduct of this research. If you have any concerns about the conduct of this research please contact my supervisor. Alternatively, for further clarification or enquiries regarding this project you can contact Professor John O'Neill (Director of Research Ethics, Massey University) by telephone on 06350 5249, or via email: humanethics@massey.ac.nz.

\section{$\underline{\text { Your Rights }}$}

This information sheet - intended to illuminate all the important aspects of my research as it pertains to you and - has been provided so that you can consider signing a consent form that would allow me to use information involving for my research. If you decide to sign for consent and at a later date you have any queries, this can be discussed. There is no pressure on you to give permission for me to review clinical records about my work with_, but I do believe the benefits outweigh the risks. You have the right to ask to be given access to a summary of the research findings once the final write-up is complete.

\section{Contact Details:}

If at any point you have any concerns or further questions about this matter, please do not hesitate to contact either myself (clerkicono@myvuw.ac.nz) or my supervisor Sarah Hoskyns (sarah.hoskyns@nzsm.ac.nz) for further information.

I look forward to hearing from you,

Conor Clerkin 


\section{APPENDIX 4: CONSENT FORM FOR FAMILY}

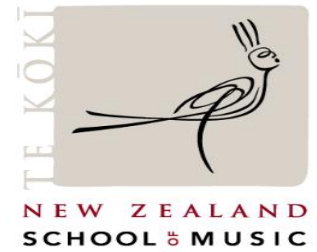

\section{Consent Form for Parents/Guardians - Record Review in a Music Therapy Research Project}

Title of Project: How are Students with Complex Needs Supported to Participate in Music Therapy: Understanding and Evaluating Interactions.

Please read the following statements and decide whether you agree with them. If you are in agreement, you will be requested to sign your name at the end of this form to indicate that you consent to the use of information involving your child for the above research project.

1. I understand that Conor Clerkin has been working in 1 as a final year student of the NZSM Master of Music Therapy Programme, and that he is required to review and evaluate information documenting his music therapy experiences in the school for the purposes of completing a research project.

2. I have read and understand the information sheet about the above study. I have had all questions answered to my satisfaction, and understand that I may continue to seek clarification from the researcher on issues pertaining to this study at any time.

3. I give consent for Conor Clerkin to review documentation involving for this study.

4. I understand that any personal information regarding people involved with the study will only be shared with the researcher's supervisor, the university committee elected to examine the research, and other trusted music therapy students and professionals of New Zealand.

5. I understand that a particular example of music therapy work with $\quad$ will be included as a vignette in the completed written exegesis to illustrate important themes in the research.

6. I understand that a case study of in music therapy will be presented and discussed at the researcher's final end-of-year examination in February 2013.

7. I understand that no real names will be used in written documents, and the location of the school will be disguised to protect the identity of those involved in this study.

8. I am aware that I may request a copy of the exegesis once it has been examined and finalised, if I so wish.

9. I am satisfied that all information about this research has been presented and communicated clearly, and hereby give my consent for the use and inclusion of data involving my child in this study.

Signed:

Print Name:

Date: 


\section{APPENDIX 5: COVER LETTER FOR SCHOOL}

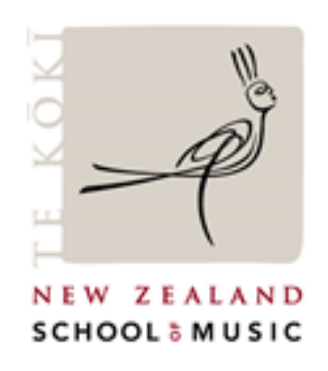

Conor Clerkin,

Master of Music Therapy Student, New Zealand School of Music, Mt. Cook, Wellington 6140, PO Box 2332

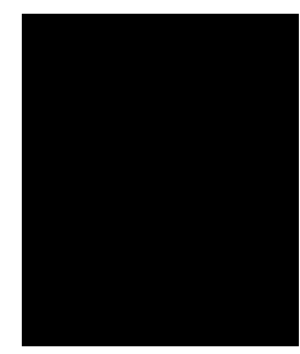

$17 / 09 / 12$

Dear

\section{RE: Music Therapy Research Study at}

The purpose of this letter is to request your permission for me to review music therapy clinical documentation - that I have been keeping as part of my practice - for research purposes. As you may know, my work at_ is a part-fulfilment of the course requirements for the Master of Music Therapy programme taught through the New Zealand School of Music. As well as having a practical component to the course, I must also carry out a research task that organises the findings from my clinical work to be presented in an exegesis paper at the end of this year.

I have the ethical approval of the Massey University Human Ethics Committee (MUHEC) to undertake a secondary analysis of data. This type of analysis means that throughout my placement it has been important for me to fulfil my clinical practice as if there was no research to be carried out in future, thus minimising any conflict of interest for me and optimising the quality of music therapy that student's receive. For school records I have attached the MUHEC approval document to this letter (HEC: Southern A Application 11/41).

I submitted a research proposal to the New Zealand School of Music Postgraduate Committee, and received their approval to research the specific question that I outlined. The approved question for my research paper is: 'How do I facilitate and support student 
participation in music therapy, and how can musical interactions be understood and evaluated?' For your information I have attached my complete research proposal. Throughout my time working in the school, I have been recording my observations and thoughts from music therapy sessions in notebooks and computers. Should I obtain the necessary permission from parents, staff and students, it is this data that will form the basis of my research.

I am in the process of composing information sheets for parents and staff, in which I will attempt to describe as clearly as possible the essence of my work at the school, including the various issues to consider before using certain data for my research. Included in these sheets will be information about myself (my background and current role), the topic of my research and what methods I will use to analyse data, as well as how data will be used and stored. It will also aim to inform people about their rights so that they can make a fullyinformed decision with which they feel safe. Following the satisfactory completion of information sheets, I will be writing consent forms so that those people who may be involved or implicated in my research can expressly state whether or not they give permission for me to use data in which they may be identifiable.

My research paper will be complete by mid-December 2012, and the school will be able to access a summary of my work following its finalisation. I welcome any questions that you might have regarding anything mentioned above, and feel free to email me (conorclerkin@hotmail.com) for more information.

Best wishes,

Conor Clerkin 


\section{APPENDIX 6: INFORMATION SHEET FOR STAFF}

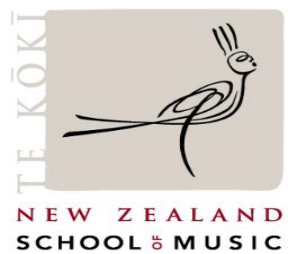

\section{Information Sheet fo Staff - Records Review in a Music Therapy Research Project}

Title of Project: How are Students with Complex Needs Supported to Participate in Music Therapy: Understanding and Evaluating Interactions

Dear

As you know, I have been working at since March of this year as part fulfilment of a Master of Music Therapy degree. I have been on placement here as part of my second year assessment to practice skills as a music therapist. As well as trying to enhance the education and wellbeing of the students at my work at the school is also aimed at helping me progress as a practitioner and researcher. I am writing to you because I would like to review documentation that was generated as part of my clinical practice within my research project. Some of the information I use may involve notes I gathered in meetings or conversations with you and it is for this reason that I am informing you about this matter now.

\section{The Research}

In my work at I quickly became interested in the qualities of interactions between myself and students in music therapy. In particular, I wished to uncover what techniques and methods I used to facilitate learning experiences for the students. I have been keeping clinical and reflective notes throughout my work to document my practice and experiences, and reviewing them by way of a 'secondary analysis'. This means that for the most part music therapy was carried out as if no research was occurring. Once I had formulated a research question based on experiences in music therapy, I began reviewing the clinical documentation with that particular focus in mind, while still continuing music therapy as it always would have been for the sake of students' learning and wellbeing.

\section{Why Records are being Requested for Review}

Currently I have permission from Massey University, the New Zealand School of Music, and to carry out my work as a music therapist and researcher. I have been recording my observations and thoughts as part of my music therapy practice with a view to improving music therapy services for the students. However, in order to use these written documents to review my practice and answer my research question, I need to gain informed consent from the school, students, their families, and any other significant parties involved. As you have been present at one or more music therapy sessions I facilitated, or spoken with me about a particular session or student I have worked with, I will need your informed consent to allow me to review records that include information involving you. Should you be happy to provide your consent this will assist me in my research that I hope will help future music therapists enhance their clinical skills for the benefit of young people with special needs. You are free to refuse and I will omit any specific information involving our work together from my data analysis. 


\section{Sources to be Used}

In the course of my work placement at I have been keeping clinical notes, a personal reflective journal, and sometimes using audiovisual recordings to enhance the accuracy and richness of my thoughts about music therapy sessions. In addition, when possible I have also been documenting personal communications with staff, students and parents in settings outside of music therapy, as well as notating music played in sessions.

\section{How Sources will be Used and Stored}

As a student acting under the ethical guidelines of Massey University and Music Therapy New Zealand, it is my responsibility to ensure that all the information I collect is treated in a way that maintains the integrity of those whom it concerns. As such, I have been and will be taking measures to safeguard records containing potentially sensitive information. The clinical notes I have written from my time at are being stored on the password protected computers in the school, meaning that only you or I can access them from there. I also keep a copy of my notes on my personal computer at home, and on a private memory disk. Any audiovisual material of students or staff in music therapy sessions that I have recorded has been quickly transferred from recording devices onto the school online server. Original recordings are then deleted from the camera. All handwritten material is kept securely in my private room at home. I am careful to disguise or omit any sensitive information in documents in order to deidentify those who are involved, and to protect the integrity of those associated with them. However, due to the nature of the small music therapy community in New Zealand as well as the type of school facility in question, it is possible that people and places may be identifiable by readers of the research.

This project has been reviewed and approved by the New Zealand School of Music Postgraduate committee. The Chairs of Massey University Human Ethics and Health and Disability Ethics Committees have given generic approval for music therapy students to conduct studies of this type, which have been judged to be low risk and, consequently, are not separately reviewed by any Human Ethics Committees. The supervisor named at the end of this information sheet is responsible for the ethical conduct of this research. If you have any concerns about the conduct of this research, please contact my supervisor or, if you wish to raise an issue with someone other than the student or supervisor, please contact Professor John O'Neill (Director of Research Ethics, Massey University) by telephone on 063505249 or via email: humanethics@massey.ac.nz.

\section{Your Rights}

This information sheet - intended to illuminate all the important aspects of my research as it pertains to you - has been provided so that you can consider signing a consent form that would allow me to utilise information involving you in my research project. If you decide to give consent and at a later date you have any queries, this can be discussed. There is no pressure on you to give permission for me to review clinical records in which you are mentioned, but I do believe the benefits will outweigh the risks. You have the right to ask to be given access to a summary of the research findings once the final write-up is complete.

\section{Contact Details:}

Should you have any concerns or further questions about this matter, please do not hesitate to contact either myself (clerkicono@myvuw.ac.nz) or my supervisor Sarah Hoskyns (sarah.hoskyns@nzsm.ac.nz) for further information.

I look forward to hearing from you,

Conor Clerkin 


\section{APPENDIX 7: CONSENT FORM FOR STAFF}

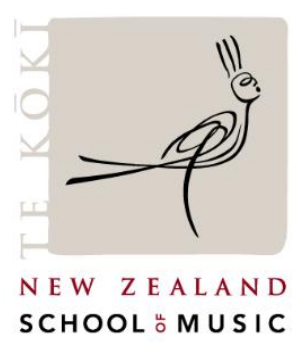

\section{Consent Form for $\quad$ Staff - Record Review in a Music Therapy Research Project}

Title of Project: How are Students with Complex Needs Supported to Participate in Music Therapy: Understanding and Evaluating Interactions.

Please read the following statements and decide whether you agree with them. If you are in agreement, you will be requested to sign your name at the end of this form to indicate that you consent to the use of data involving you for the above research project.

1. I understand that Conor Clerkin has been working in s a final year student of the NZSM Master of Music Therapy Programme, and that he is required to review and evaluate information documenting his music therapy experiences in the school for the purposes of completing a research project.

2. I have read and understand the information sheet about the above study. I have had all questions answered to my satisfaction, and understand that I may continue to seek clarification from the researcher on issues pertaining to this study at any time.

3. I give consent for Conor Clerkin to review documentation involving me for this study.

4. I understand that any personal information regarding people involved with the study will only be shared with the researcher's supervisor, the university committee elected to examine the research, and other trusted music therapy students and professionals of New Zealand.

5. I understand that a case study will be presented and discussed at the researcher's final end-ofyear examination in February 2013, and that information involving me may be included in it.

6. I understand that no real names will be used in written documents, and the location of the school will be disguised to protect the identity of those involved in this study.

7. I am aware that I may request a copy of the research paper once it has been examined and finalised, if I so wish.

8. I am satisfied that all information about this research has been presented and communicated clearly, and hereby give my consent for the use and inclusion of data involving me in this study.

Signed:

Print Name:

Date: 


\section{Too Strong}

\section{Upbeat}

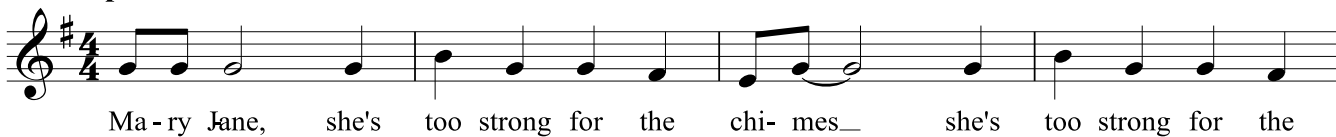

Ma-ry Jane, she's too strong for the chi- mes_ she's too strong for the
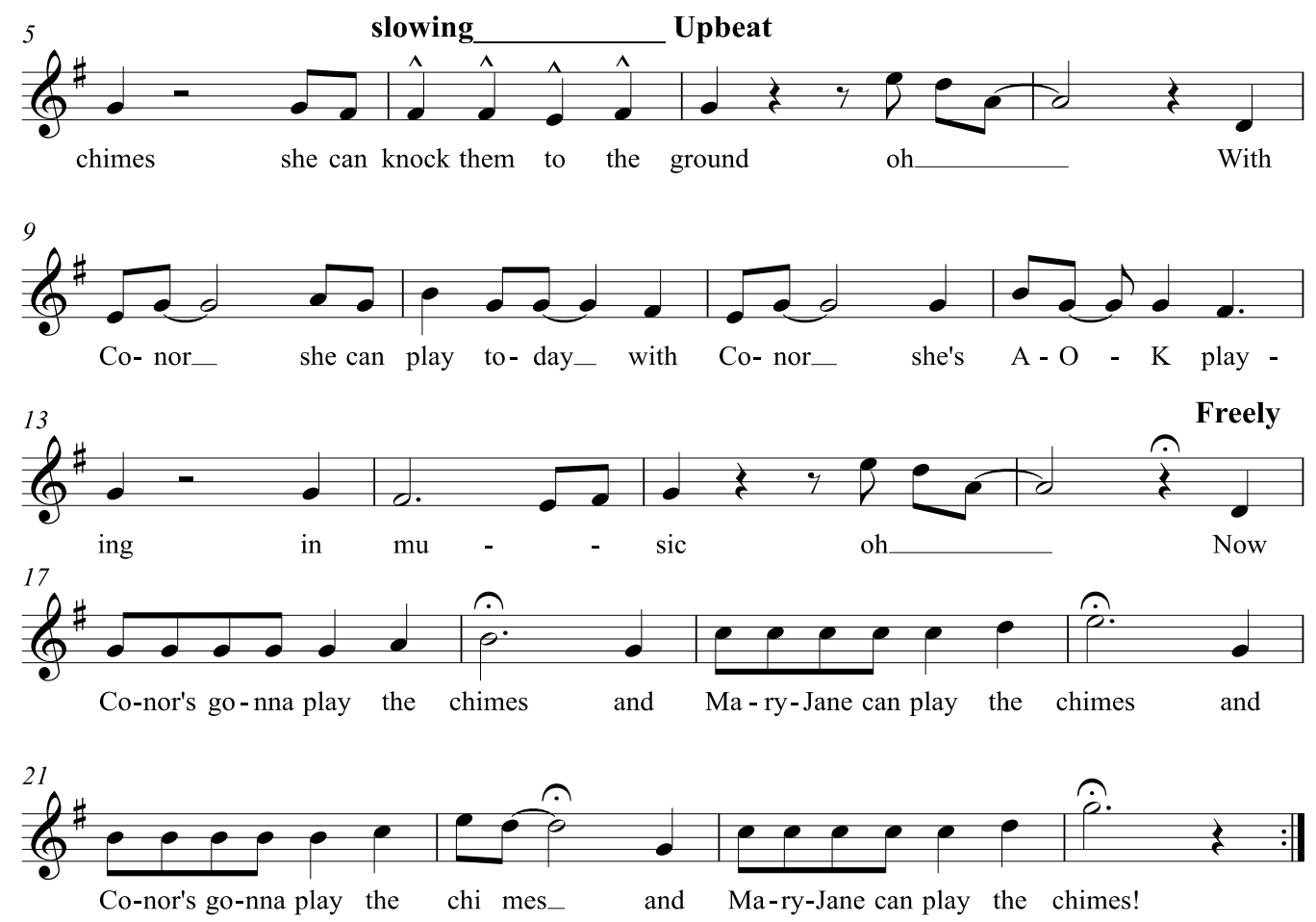
I usually played this special song near the end of my sessions with Mary-Jane, because I felt that it could give us both something extra to look forward to. Before playing it I would usually create a space for non-musical interaction, as I talked to Mary-Jane and set up the chimes beside her stronger right arm, responding to her expressions, movements and vocalisations as I did so. I usually counted in "1, 2 -1, 2, 3, 4" emphatically before singing the lyrics for the first time.

There were many variations on this song, with different lyrics and melodic changes. What I have notated and written here is only an example of some of the ways we used and adapted the song. However, I always played it in the key of G with the chord progression of G-C-G-DG-D every 8 bars, with the exception of bars 17-24 in this example where the progression changed to G (pause)-C(pause)- G(pause)- C(pause). I frequently changed strumming patterns to keep the song rhythmically fresh.

The first 8 bars are what existed from the very first time we played the song together, with words and melody remaining the same in this section for all of our sessions after its creation. At bar 6, I usually - but not always - slowed down and emphasised each word leading up to "ground" to invite Mary-Jane to play, and this is one place where she often struck the chimes. Bars 9-19 show one of the variations that we developed later on, and I especially remember how Mary-Jane laughed when I sang this part initially, which prompted me to play it again in future. It was a section when I did not try to implicitly or explicitly invite Mary-Jane to play, but if she wanted to she could and did!

The final 8 bars shown here developed about half way through our sessions together, and every time I began this section Mary-Jane laughed energetically. I thought it was good to ease into this section and let Mary-Jane simply laugh for as long as she needed to while I modelled the turn-taking by playing the chimes first in the pause. When we got to her turn, often I had to wait for some time before her laughing subsided, and then she usually directed her focus and energy to playing the chimes. The pauses I incorporated into this section allowed for us to wait in a natural way and take our time when we played, but if Mary-Jane decided not to play during her turn, I accepted this and played on if I felt it was appropriate. 


\title{
APPENDIX 9: EXAMPLES OF EARLY AND LATE CODING
}

\author{
EXAMPLE OF EARLY CODING
}

\section{Tuesday, March 20th}

Mary-Jane, 11:00-11:35

Mary-Jane has a cortical visual impairment, and a staff member who helps with visual needs joined me in the session today - my first with Mary-Jane. I placed the chimes to her right side (and maybe next time I can try the left side) I also made available a tambourine and small drum. The staff member made her aware of the choice available, and Mary-Jane played on the chimes after hearing the word "drum", indicating that that was her preference of the two, or so it was understood. This surprised her slightly, as understandably she suspected it might have been too complicated a way of signalling choice. I first sang 'Day-O' (what a day-o for music). In the first verse I included Mary-Jane's name, describing her surroundings and environment. She played the chimes at appropriate rhythmical and structural points, sometimes following lyrical prompts in her responses. Secondly I sang 'I've got the drum'. When I passed it on to Mary-Jane she did not play it, but perhaps I did not make it clear enough that that is how the game is meant to work. I finished singing the words "I want the drum, I do, I do!". Then I played 'I see the sea' - maybe I should get the ocean drum for effect and colour next time. When I said "wave" at a point of (intended) anticipation, Mary-Jane played the chimes for the first time in the song, indicating possible awareness of structure and expectations. As in most songs, I mentioned Mary-Jane's name in the lyrics here, saying that I saw her in the sea. I feel this may have helped her engage at certain points. In 'Raindrops keep falling on my head', Mary-Jane played the chimes at various times, and when she did so when I wasn't singing I resumed singing as a consequence of her action, which I hope she noticed. D came in and was a bit silly, singing S Club 7 and 'A spoonful of Sugar' in a posh English accent. Mary-Jane seemed to enjoy this, as she laughed and smiled at D's rendition. When D and the other staff member left, I continued playing Mary-Jane 'She'll be Coming round the Mountain'. During this activity Mary-Jane increased her vocality and her breathing noticeably increased in volume (noise). I tried reflecting Mary-Jane's sounds and allow them to influence my playing. I need to learn more about her signals though to gain a better understanding of whether she is content or distressed. Finally, when the staff member re-entered I decided to wind the session down. Mary-Jane's facial expression had changed from the rest of the session, but I don't know why. I played a slow chord pattern in A minor, leaving Mary-Jane free to fill the vocal space.

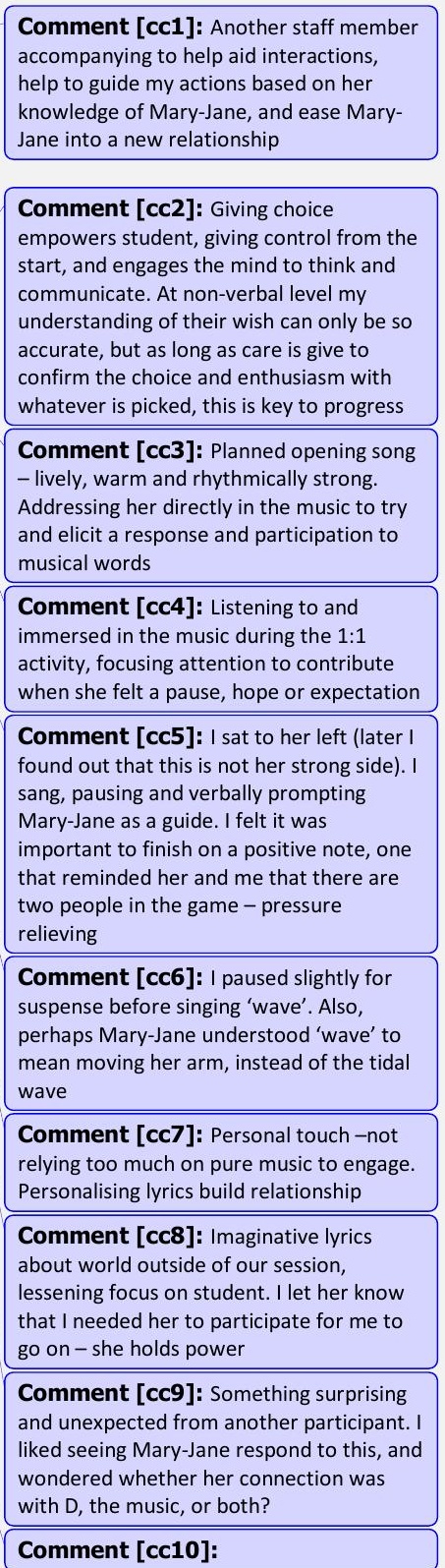




\section{EXAMPLE OF LATER CODING}

\section{Wednesday, August 22nd}

\section{T, 12:05-12:25, Sensory Room}

I collected $\mathrm{T}$ from the classroom, and she was extremely vocal and seemed physically energised when we entered the music room, as she waved her arms around and began smiling strongly for 1-2 minutes. Her active participation and contribution following this initial excitement (perhaps caused by her anticipation of music) was less frequent and less spontaneous. I tried to stick closely to what we played together last week, as T seemed to engage well with it. Interacting with her vocal communication and physicality from the start, I reflected her sounds and movement back to her. Once she had appeared to have calmed down a little, I began singing 'Hello T' (to tune of 'I like Candy'), and she had the chimes to play to her left. T later chose the tambourine over the chimes when given the choice by playing it strongly with her right arm, and with her I played 'Congratulations' for this with portions of more improvised section as well depending on her movement and participation. Remembering her success in the past session with the xylophone, I wanted to give $\mathrm{T}$ another opportunity to learn about this instrument and play it. E held it for her, and $\mathrm{E}$ herself played frequently in an attempt to entice T into an interaction. Personally I felt that her playing was too frequent and may not have left enough space and time for $\mathrm{T}$ to understand that she had control over what sound it could make. E's playing was musical in a melodic sense, but it seemed that there were no clear invitations communicated to $\mathrm{T}$, other than verbal prompts, albeit very gentle. In my next session with her, when playing the xylophone I think I will try to position the xylophone so that it does not need the support of another person, and so that it is easily accessible to T. In this way $\mathrm{T}$ will be able to be completely independent instrumentally, and nobody else will be tempted to fill in her spaces. I want $\mathrm{T}$ to feel comfortable, and to feel the desire to communicate with me when I play, either using her voice or through her instrument. When T managed to hold a mallet, she dropped it on the xylophone to make a sound. It might be an idea to create a 'dropping song' to accommodate these skills better in a musical way, and to synchronise our playing better, or alternatively I could try to support the movement of her hand back towards the xylophone while still holding the mallet so that $\mathrm{T}$ can receive sensory feedback about what it feels like to hit the keys and hear an exact note that she directly played. I realised quite early in the session that I had forgotten the words to the song I wrote last week for T, called after her and sung to the tune of 'Valerie'.

Comment [cc19]: This section is mostly
comprised of reflections that allude to
several codes, such as: Leaving space for
anticipation, slowing and pausing,
challenging.
$\begin{aligned} & \text { Comment [cc20]: Pre-composed song, } \\ & \text { structure consistently }\end{aligned}$

Comment [cc11]: Transitioning

Comment [cc12]: Structure consistently

Comment [cc13]: Developing sounds

Comment [cc14]: Pre-composed song Comment [cc15]: Offer choice

Comment [cc16]: Responding to movements

Comment [cc17]: Change instrument

Comment [cc18]: Sharing instrument 


\section{SEPTEMBER 1 ST}

Expect to wait in new songs

Staff sharing

Boundary and space invitation

Music framework with adapted lyrics

Familiar song

Instruction clarity - challenging question/suggestion

Rubato/pause

Watching body language

Reflection

Music therapy interception

Imitate - attention, exploration

Music transition walk

Developing content

After music move

Flexibility with able bodied

Describing, informing, preparing

Re-engagers - behaviours that bring back

Voicing - encourage voice/singing (challenging?)

Body placement/positioning

Re-use newly composed songs

Same/different instrument

Acknowledging

Listening

Persisting

Choosing positive interpretations

Touching/gesturing for contact 
Repetition/familiarising

Changing, not end music

Naming

Eye contacting

Physically supporting

Both arms

Intensifying and relaxing

\section{SEPTEMBER 24TH}

Following and Inviting (Distinguishable? Constant shifting between the two)

Developing vocal germ without words

Adapt Lyrics - naming, challenging question/suggestion (can)/music

Keeping expectations for participation in check for new songs

Persisting/experimenting even if initially activity is seemingly un-engaging

Drop back/out (if sound is becoming overwhelming)

Familiar songs - expression, slowing to increase anticipation/ indicate my expectation

Imitate

Using re-engaging techniques to encourage participation (individual to students)

\section{Being physically resourceful and aware}

Watching body language

Eye contacting

Considering and changing body placement

Touching/gesturing for contact (end in itself)

Physical Support - helping and scaffolding (end is to play instrument)

Give attention to and opportunities to use both sides of body

Acting/dancing to music 


\section{Being musically resourceful}

Not singing or talking - gives time for both participants to think

Journeying and returning (going off the main melody for an extended period in response to vocalisations or melodies of students, before seamlessly resuming the song)

Using repetition to familiarise

Improvising new personalised songs that are co-created as a reflection of each other. Encapsulating an event or feeling in a song that brings back uplifting memories.

(contact song)

Using sharp contrasts with musical elements - eg. rhythm, dynamics, tempo.

\section{Structuring clearly}

Reviewing and evaluating past sessions

Describing, informing, preparing

Being consistent with song/activity choice

Considering instruments that enable, and those that distract

Changing instruments with activities (increase opportunities by offering varied ways)

Clear finishing cadences and musical signs

Nearly always: Staff sharing.

Bringing to a private room for music.

Being relaxed, playful and genuine.

Smiling and laughing/ sit back and take stock

Acknowledging behaviours and wishes (especially when unexpected or not in plan).

Recognise own psychological needs and feelings to reflect and refocus on client. 


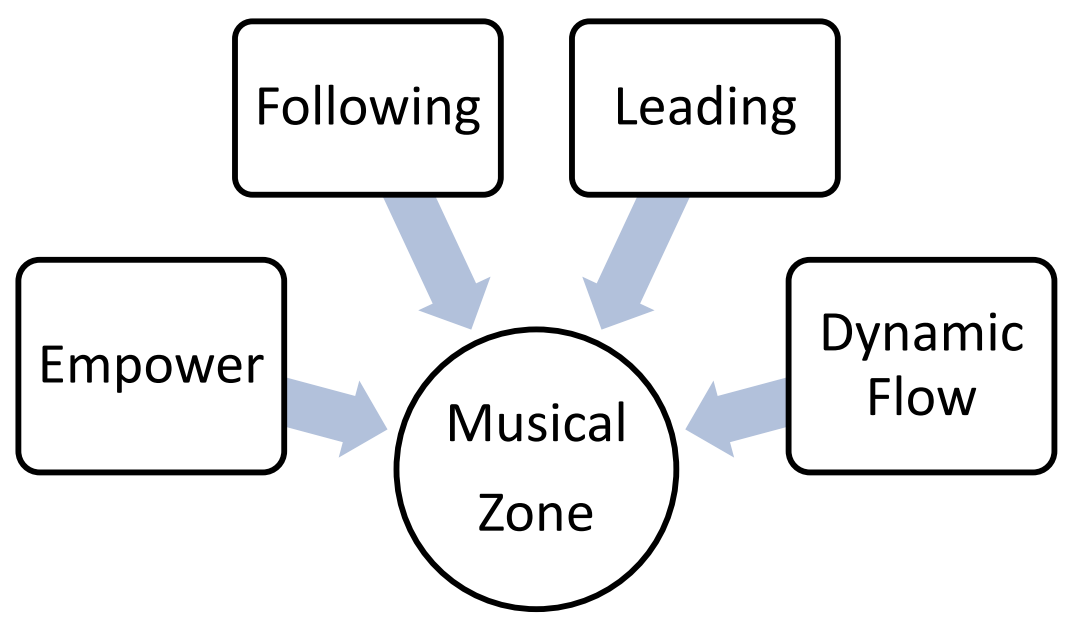

\section{Empower and Include}

Provide accessible instruments

Offer a choice

Discover likes and preferences

Describing, informing, and preparing

Involve in 'extra-musical' activities

Familiarising with session structure

\section{Following}

Developing sounds

Not using words in music

Using contrasting musical elements in reflection

Playing without expectations

Not being too 'dominant' (in terms of waiting statically on an unresolved chord expectantly for length of time that reduces the dynamic flow)

Watching body language and movements 


\section{Leading and Inviting}

Using repetition

Using popular/pre-composed songs

Naming

Challenging with a suggestion/request

Leaving a sentence/musical cadence unfinished

Touching

Using contrasting musical elements, and slowing down at phrase endings

Physically supporting to make sound

Transitioning to and from class

Dynamic Flow - keeping things interesting, facilitating participation through leading and following of both participants

Physically moving (changing position or dancing)

Give attention to both sides of body

Singing about Me, We, and You (not just You)

Journey and return (allowing repetitive songs or activities to have a freer improvisatory structure with few or no words for a period, before returning to 'base')

Changing and sharing instruments

Using contrasting musical elements 


\section{Increasing student sense of safety, control, and contact}

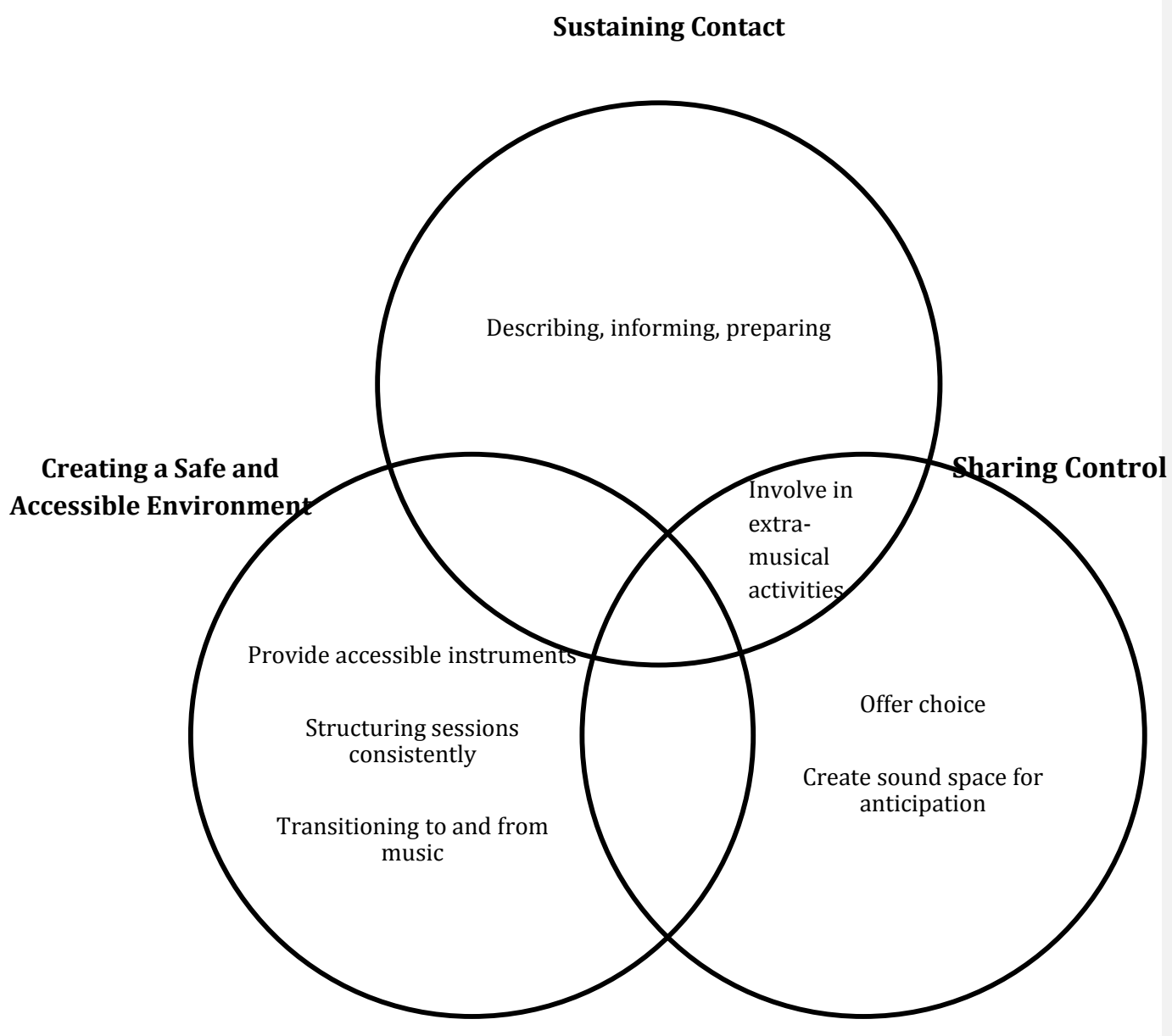




\section{Following and Leading}

Following

Leading

\begin{tabular}{|l|l|l|}
\hline Developing sounds & $\begin{array}{l}\text { Timing } \\
\text { when to } \\
\text { Not using words in music }\end{array}$ & Using Repetition \\
Playing without & $\begin{array}{l}\text { when to } \\
\text { expectations }\end{array}$ & Using pre-composed songs \\
Watching body movements & $\begin{array}{l}\text { Using } \\
\text { student's } \\
\text { vocal }\end{array}$ & $\begin{array}{l}\text { Touching } \\
\text { Physically supporting to } \\
\text { play instrument/dance }\end{array}$ \\
& sounds & Slowing down at phrase \\
& Contact & ends \\
& song & \\
\hline
\end{tabular}

\section{Keeping the dynamic flow}

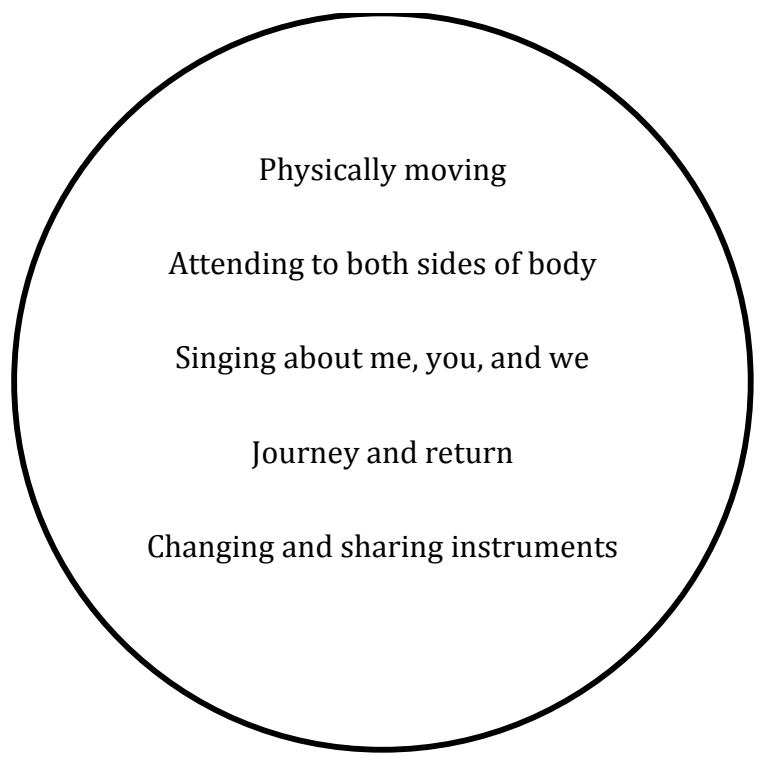




\section{Using musical contrasts}

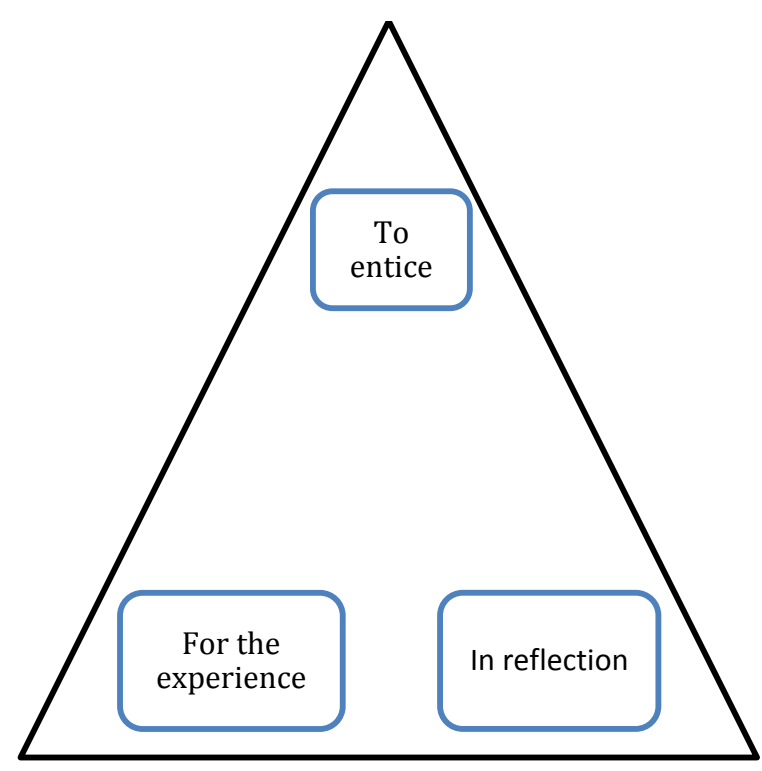

